\title{
Tyrosine Hydroxylase in the Rat Parabrachial Region: Ultrastructural Localization and Extrinsic Sources of Immunoreactivity
}

\author{
T. A. Milner, T. H. Joh, and V. M. Pickel \\ Laboratory of Neurobiology, Department of Neurology, Cornell University Medical College, New York, New York \\ 10021
}

We sought to determine (1) the ultrastructural localization and (2) the extrinsic sources of the catecholamine-synthesizing enzyme, tyrosine hydroxylase (TH), in the lateral parabrachial region (PBR) of adult male rats. In the first portion of the study, a rabbit antiserum to TH was immunocytochemically localized in coronal sections through the lateral PBR from acrolein-fixed brains using the peroxidase-antiperoxidase method. Electronmicroscopic analysis revealed that perikarya and dendrites with peroxidase immunoreactivity for TH constituted only $17 \%$ of the total labeled profiles. Afferents to the TH-labeled perikarya and dendrites usually failed to exhibit immunoreactivity and were thus considered noncatecholaminergic. Somatic synapses were most commonly detected on small immunoreactive perikarya in the central lateral nucleus of the PBR. Other labeled perikarya located in the dorsal lateral or ventral lateral nuclei received few somatic synapses and were morphologically distinct in terms of their larger size, infolded nuclear membrane, and abundance of cytoplasmic organelles. Axons and axon terminals with peroxidase immunoreactivity constituted the remaining labeled profiles in the lateral PBR. These terminals primarily formed symmetric synapses with unlabeled and a few labeled dendrites. The labeled axon terminals were categorized into 2 types: Type I was small $(0.3-0.6 \mu \mathrm{m})$, contained many small clear vesicles, and exhibited few well-defined synaptic densities. The second type was large $(0.8-1.4 \mu \mathrm{m})$, contained both small clear and large dense core vesicles, and exhibited well-defined synaptic densities. The 2 types of terminals were morphologically similar to dopaminergic terminals.

The location of catecholaminergic neurons contributing to the TH-labeled terminals was determined by combining peroxidase-antiperoxidase immunocytochemistry for $\mathrm{TH}$ with retrograde transport of wheat germ agglutinin-conjugated horseradish peroxidase (WGA-HRP). The tracer was unilaterally injected into the PBR of anesthetized adult rats. Immunocytochemical labeling for TH was seen as a brown reaction product within neurons in known catecholaminergic cell groups. A black granular reaction product formed by a cobalt-intensified and diaminobenzidine-stabilized tetramethyl benzidine reaction for WGA-HRP was evident within many TH-labeled and unlabeled neurons. Dual localization of the immunocytochemical and transport markers was seen within groups of catecholaminergic neurons primarily located ipsilateral to the injection in the medial nucleus of the solitary tract, area postrema, caudal and

\footnotetext{
Received Sept. 30, 1985; revised Mar. 3, 1986; accepted Mar, 3, 1986.

We would like to thank June Chan for technical assistance, Bill Feig for photographic assistance, and Hector Cornejo for computer assistance. This work was supported by NIH grants HL 18954 and MH 00078 (V.M.P.) and by an NIH Postdoctoral Fellowship NS 07340 (T.A.M.).

Correspondence should be addressed to Dr. Virginia M. Pickel, Laboratory of Neurobiology, Cornell University Medical College, 411 E. 69th Street, New York, NY 10021.

Copyright (C) 1986 Society for Neuruscience $0270-6474 / 86 / 092585-19 \$ 02.00 / 0$
}

rostral ventrolateral medulla, locus coeruleus, and paraventricular nucleus of the hypothalamus. The regional distributions of the afferent catecholaminergic neurons support the concept that dopamine, as well as noradrenaline and adrenaline, may be an important transmitter in afferent pathways to the PBR.

The catecholamines and their biosynthetic enzymes, tyrosinc hydroxylase (TH), dopamine- $\beta$-hydroxylase (DBH), and phenylethanolamine $\mathrm{N}$-methyltransferase (PNMT) are found in the dorsolateral tegmentum, including the major noradrenergic cell group of the locus coeruleus and catecholaminergic perikarya and processes in the lateral parabrachial region (PBR) (Dählström and Fuxe, 1964; Levitt and Moore, 1979; Milner et al., 1984; Ruggiero et al., 1985; Swanson and Hartman, 1975). The importance of catecholamines in autonomic functions involving the lateral PBR has been suggested by a number of physiological and pharmacological studies (Hedreen, 1980; Loewy and McKellar, 1980; Mraovitch et al., 1982). However, a morphological substrate for interactions of catecholaminergic neurons in the PBR has not been determined. Moreover, most of the sources of the catecholaminergic terminals in the PBR are unknown, but they may include both intrinsic perikarya and extrinsic groups of catecholaminergic neurons. Two likely candidates for extrinsic catecholaminergic afferents include the medial nuclei of the solitary tracts (m-NTS) and the hypothalamus. Both regions contain perikarya immunoreactive for the catecholamine synthesizing enzymes (Armstrong et al,, 1982b; Hökfelt et al., 1984b; Kalia et al., 1985a, b; Ruggiero et al., 1985) and contribute efferents to the PBR (King, 1980; Loewy and Burton, 1978; Norgren, 1978; Saper et al., 1976). Furthermore, Mantyh and Hunt (1984) have combined retrograde transport of fluorescent dyes with immunocytochemical localization of TH to demonstrate that the m-NTS is one of the sources of catecholaminergic terminals in the PBR. However, whether other groups contribute efferents to the PBR is not known. As the enzyme that catalyzes the first step in the biosynthesis of catecholamines, TH serves as a useful marker for further investigation of the synaptic associations and sources of catecholaminergic neurons in the PBR.

In this study, we used the peroxidase-antiperoxidase (PAP) method (Sternberger, 1979) to determine (1) the ultrastructural localization of a rabbit polyclonal antiserum to TH and (2) the location of perikarya that contained both TH immunoreactivity (TH-I) and retrograde transport of wheat germ agglutinin-conjugated horseradish peroxidase (WGA-HRP) following unilateral stereotaxic injections into the PBR.

\section{Materials and Methods}

\section{Animals}

Forty-eight (200-250 g) male Sprague-Dawley rats from Hilltop Lab Animals, Inc., were used in these studies. Twenty-three of the rats were 
anesthetized with halothane $\left(2 \%\right.$ in $\left.100 \% \mathrm{O}_{2}\right)$ and received an intraventricular injection of colchicine ( $100 \mu \mathrm{g}$ in $7.5 \mu \mathrm{l}$ saline; Sigma) $1 \mathrm{~d}$ prior to sacrifice (Ljungdahl et al., 1978). In the transport studies $1 \mathrm{~d}$ survival after colchicine treatment was experimentally determined to be optimal for enhancing the detectable levels of TH-I without significantly reducing retrograde transport of WGA-HRP.

\section{Electron-microscopic immunocytochemistry}

Ten non-colchicine-treated animals were fixed by perfusion with $75 \mathrm{ml}$ of $3.75 \%$ acrolein (Polysciences) and $2 \%$ paraformaldehyde in $0.1 \mathrm{M}$ phosphate buffer ( $\mathrm{pH} 7.4$ ) followed by $200 \mathrm{ml}$ of $2 \%$ paraformaldehyde in $0.1 \mathrm{M}$ phosphate buffer. Coronal Vibratome sections, $30-40 \mu \mathrm{m}$ thick, were collected through the PBR and then immunocytochemically labeled with a polyclonal antiserum to $\mathrm{TH}$. The antiserum was prepared in rabbit and checked for specificity and cross-reactivity by methods described previously (Joh and Ross, 1983; Joh et al., 1973; Pickel et al., 1975). The labeling procedure was a modification (Pickel, 1981; Pickel et al., 1975) of the PAP method of Sternberger (1979). Briefly, this procedure consisted of sequential incubation of the sections with (1) a 1:2000 dilution of the primary antiserum; (2) a 1:50 dilution of goat anti-rabbit immunoglobulin (IgG); and (3) a 1:100 dilution of PAP (rabbit) complex. The dilutions and washes separating each of the incubations were prepared with $0.1 \mathrm{~m}$ Tris-saline $(\mathrm{pH} 7.6)$ containing $1 \%$ normal goat serum. All incubations were at room temperature and had durations of 18-20 hr for the primary antiserum and $1 \mathrm{hr}$ each for the IgG and PAP. The bound peroxidase was demonstrated by reaction with 3,3'-diaminobenzidine (DAB) and hydrogen peroxide.

The labeled sections were postfixed $1 \mathrm{hr}$ in $2 \%$ osmium tetroxide in $0.1 \mathrm{M}$ phosphate buffer, dehydrated, and embedded in Epon 812 between 2 plastic coverslips. Regions of the lateral PBR containing TH-I were selected prior to embedding the tissue in beam capsules using the criteria described previously (Milner et al., 1984). The terminology for the subdivisions of the lateral PBR is that of Fulwiler and Saper (1984). Ultrathin sections were collected on grids from the surface of the plasticembedded tissues, counterstained with uranyl acetate and lead citrate, and examined with a Philips $201 \mathrm{EM}$. Eight of the animals that showed the best immunocytochemical labeling and preservation of ultrastructural morphology were used in the quantitative cvaluation. From cach of these animals, at least 6 grids containing 2-5 thin $(500 \AA)$ sections were collected from the surface of 2 or more plastic-embedded Vibratome sections. All labeled profiles within 1 thin section from each grid were photographed and used in the final tabulation.

\section{Retrograde transport and light-microscopic immunocytochemistry}

To demonstrate that neither the transport of WGA-HRP nor immunocytochemical labeling was compromised by combining the methods, immunocytochemical labeling for TH and retrograde transport of WGAHRP were first examined independently.

\section{Light-microscopic immunocytochemistry}

In an independent immunocytochemical study, the brains from 5 colchicine-treated and 5 normal animals were processed for the localization of $\mathrm{TH}$ as described above except that (1) the fixative was $2 \%$ parafor-

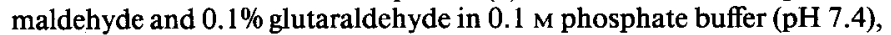
(2) the incubation with primary antiserum included $0.25 \%$ Triton-X 100 , and (3) the sections were not postfixed with osmium or embedded for electron microscopy. The labeled sections were then mounted on glass slides coated with $1 \%$ gelatin, dehydrated, cleared, and coverslipped. The distribution of perikarya with TH-I was examined in coronal sections taken at the same levels as those examined for retrograde transport (see sections immediately below).

\section{HRP histochemistry}

In the independent transport study, 16 animals were anesthetized with halothane $\left(2 \%\right.$ in $\left.100 \% \mathrm{O}_{2}\right)$, and $10-30 \mathrm{nl}$ of $1 \%$ or $10 \%$ WGA-HRP in sterile saline was injected unilaterally into the PBR using a glass mi- cropipette attached to an air-pressure delivery system (Amaral and Price, 1983). The stereotaxic coordinates were based upon the atlas of Paxinos and Watson (1982). After a $24 \mathrm{hr}$ survival, 10 of the animals were anesthetized with Nembutal $(50 \mathrm{mg} / \mathrm{kg}$, i.p.) and the brains were fixed for $30 \mathrm{~min}$ by an aortic arch perfusion with $500 \mathrm{ml}$ of $1 \%$ paraformaldehyde and $1.25 \%$ glutaraldehyde in $0.1 \mathrm{M}$ phosphate buffer (pH 7.4) followed by $250 \mathrm{ml}$ of $10 \%$ sucrose in $0.1 \mathrm{M}$ phosphate buffer. Six of the animals were injected with colchicine $24 \mathrm{hr}$ after injection of the WGA-HRP and survived an additional $24 \mathrm{hr}$ prior to sacrifice. Coronal $(40 \mu \mathrm{m})$ frozen sections from these brains were processed for the histochemical demonstration of HRP according to the procedure of Mesulam (1978). Briefly, the sections were mounted on slides coated with $1 \%$ gelatin and air-dried for $15-20 \mathrm{~min}$. They were then presoaked at room temperature for $20 \mathrm{~min}$ in the dark in a solution containing 0.01 $\mathrm{M}$ acetate buffer (pH 3.3), 1\% sodium nitroferrocyanide, $2.5 \%$ ethanol, and $0.005 \%$ letramethylbenzidine (TMB). Three milliliters of $0.3 \% \mathrm{H}_{2} \mathrm{O}_{2}$ was added to this solution, and the sections were incubated for an additional $20 \mathrm{~min}$. The sections were finally dehydrated and mounted under coverslips for microscopic examination.

\section{Light-microscopic retrograde transport combined with immunocytochemistry}

In the combined transport and immunocytochemical studies, 12 rats received intraventricular colchicine $24 \mathrm{hr}$ after a $30 \mathrm{nl}$ injection of the WGA-HRP (the optimal amount and concentration of WGA-HRP were determined from the results given above) and $20-24 \mathrm{hr}$ prior to sacrifice. The rats then were anesthetized with Nembutal $(50 \mathrm{mg} / \mathrm{kg}$, i.p.) and were perfused through the ascending aorta with $400 \mathrm{ml}$ of $2 \%$ paraformaldehyde and $0.1 \%$ glutaraldehyde in $0.1 \mathrm{~m}$ phosphate buffer (pH 7.4). The brains were removed and transferred to fresh fixative for $30 \mathrm{~min}$, then to a solution of $10 \%$ sucrose in $0.1 \mathrm{M}$ phosphate buffer for 12-24 $\mathrm{hr}$ at $4^{\circ} \mathrm{C}$. Coronal $(30 \mu \mathrm{m})$ sections were cut on a sliding microtome. The sections were collected in $0.1 \mathrm{M}$ phosphate buffer and processed for the histochemical demonstration of HRP according to the TMB procedure described above. The sections were then rinsed in $0.01 \mathrm{~m}$ acetate buffer followed by a brief $5 \mathrm{sec}$ rinse in $0.1 \mathrm{~m}$ phosphate buffer. The reaction product was stabilized by a $4 \mathrm{~min}$ incubation in a solution of $0.05 \% \mathrm{DAB}, 0.02 \%$ cobalt acetate, and $0.01 \% \mathrm{H}_{2} \mathrm{O}_{2}$ in $0.1 \mathrm{M}$ phosphate buffer at $\mathrm{pH} 7.4$ (Rye et al., 1984). Finally, the sections were immunocytochemically labeled for TH by the method described under electron-microscopic immunocytochemistry.

Sections processed for single and dual labeling were examined using both brightfield and Nomarski optics on a Leitz microscope. Regional maps indicating the distribution of cells that contained TH-I and the retrogradely transported WGA-HRP were drawn by means of a camera lucida attachment on the light microscope. On the maps, each coronal section was separated by a distance of $0.4 \mathrm{~mm}$, and each symbol represented 1 neuron, unless otherwise indicated. The dense central zone of the injection site was distinguished from the diffusion spherc using an image analyzer (Eyecom II; PDP11-45).

\section{Results}

\section{Ultrastructural localization of $\mathrm{TH}$}

Electron-microscopic analysis of portions of the lateral PBR containing the most intense light-microscopic labeling for $\mathrm{TH}$ (Milner et al., 1984) revealed that perikarya with TH-I constituted only $3 \%$ (15 out of 625 ) of the total labeled profiles. Two types of labeled perikarya were observed. The first was found within either the dorsal lateral or ventral lateral nuclei described by Fulwiler and Saper (1984). These perikarya were medium sized (18-20 $\mu \mathrm{m}$ in longest cross-sectional diameter) and elongated (Fig. 1A). Their unlabeled nucleus contained a prominent nucleolus and exhibited a slightly infolded membrane. An abundant mass of cytoplasm contained numerous mitochondria, rough endoplasmic reticulum, Golgi apparatus, lysosomes, and a few

Figure 1. Ultrastructural localization of TH-I within 2 different types of neuronal perikarya in the PBR of a normal rat. $A$, Low-magnification micrograph shows a TH-I perikarya found in the ventral lateral nucleus, which contains an unlabeled nucleus $(N)$ with a prominent nucleolus and 

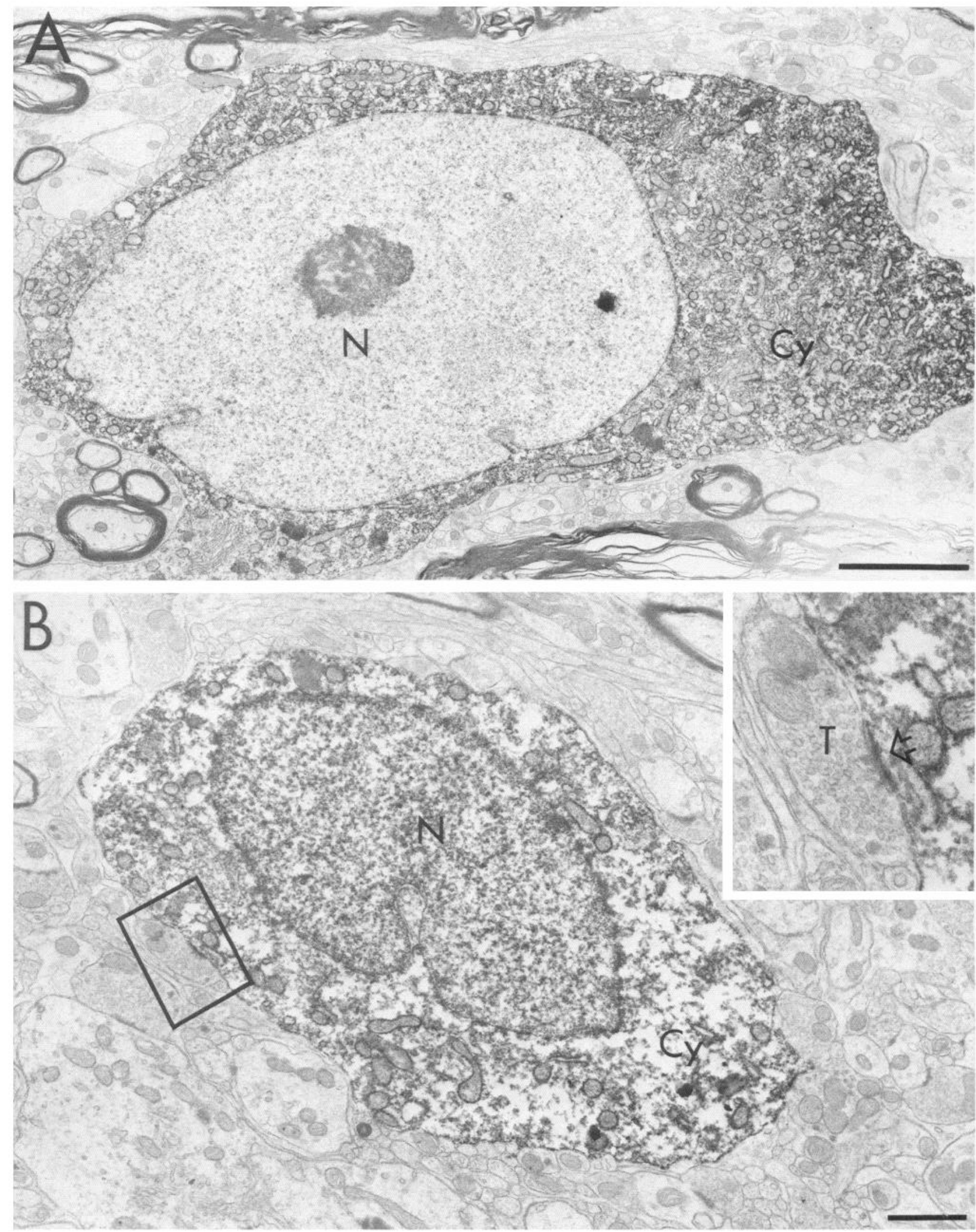

an abundant mass of cytoplasm $(C y)$ with numerous mitochondria, rough endoplasmic reticulum, Golgi apparatus, lysosomes, and a few vesicles. $B$, Second type of TH-I perikarya is found in the central lateral nucleus, which contains a nucleus with a highly invaginated nuclear membrane and a thin rim of cytoplasm with only a few organelles. Boxed area enlarged in right-hand corner shows a portion of the plasma membrane that receives a symmetric contact (open arrow) from an unlabeled axon terminal $(T)$ containing many small clear, and a few dense, core vesicles. Bar, $2 \mu \mathrm{m}(A), 1.0 \mu \mathrm{m}(B)$. 

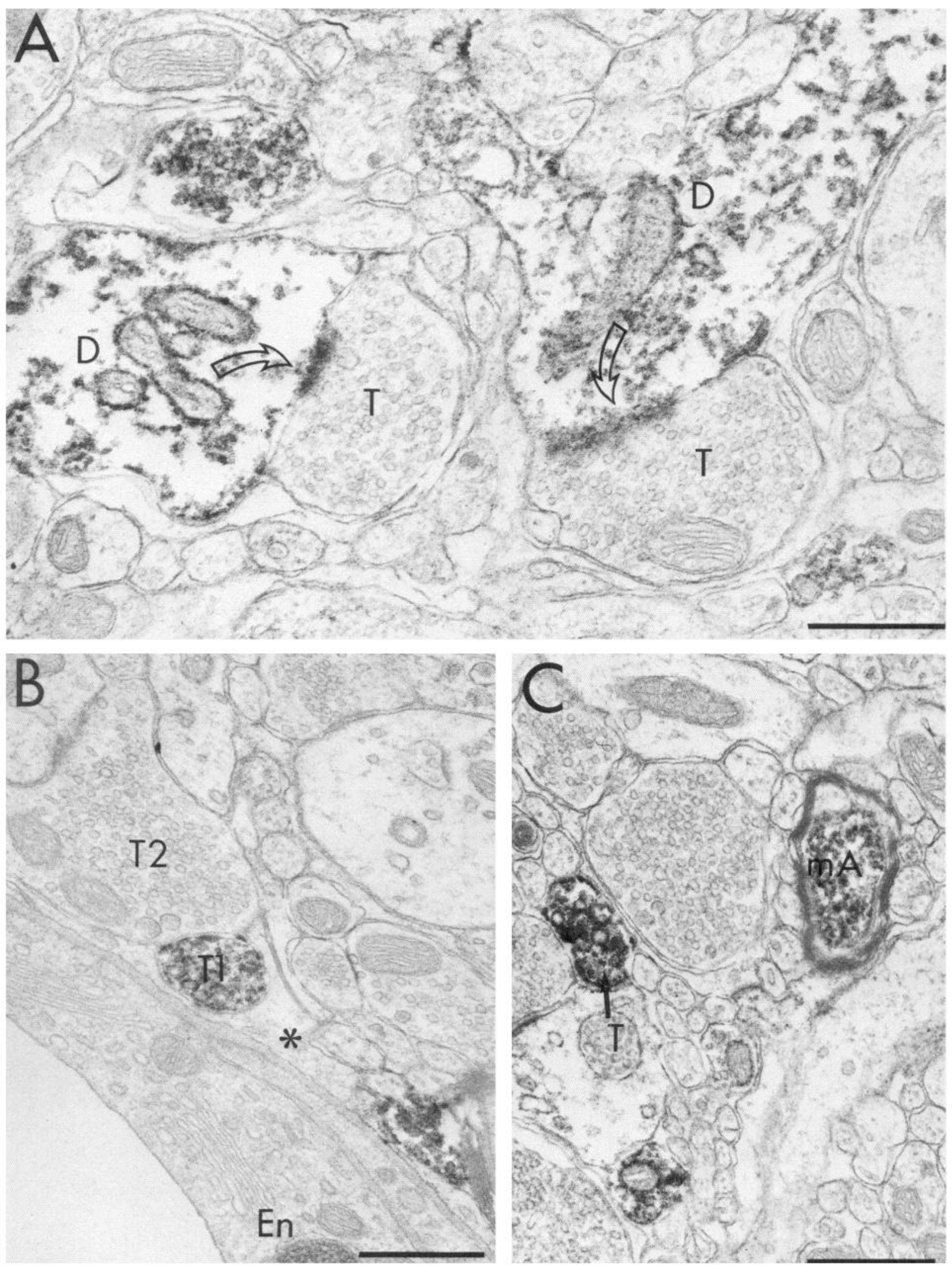

Figure 2. A, Proximal and distal dendrites $(D)$ of TH-I perikarya are contacted by unlabeled terminals $(T)$ forming primarily asymmetric synapses (open arrows). B, Small type I terminals containing TH-I $(T I)$ are sometimes found partially surrounded by an astrocytic process $\left({ }^{*}\right)$ both adjacent to the basement membrane of the endothelial cell of a blood vessel and to unlabeled terminals $(T 2)$. $C$, Rarely, a myelinated axon $(m A)$ containing TH-I is found. A small type I terminal $(T)$ is also shown. Bar, $0.5 \mu \mathrm{m}$. 
vesicles. This type of immunoreactive perikarya received few somatic synapses.

The second type of perikarya with cytoplasmic labeling for TH was found in the central lateral nucleus of the PBR described by Fulwiler and Saper (1984). These cells were small (8-10 $\mu \mathrm{m}$ in longest cross-sectional diameter) and round or spindle shaped (Fig. $1 B$ ). The nuclear membrane was highly invaginated and enclosed clumps of heterochromatin and electron-dense material. A thin rim of cytoplasm contained a few mitochondria, saccules of smooth and rough endoplasm reticulum, lysosomes, and a few vesicles. Axosomatic synapses were common on the second type of labeled perikarya (Fig. $1 B$ ). The unlabeled presynaptic terminals measured $0.3-1.4 \mu \mathrm{m}$ and contained mitochondria and numerous small, clear (scv), and a few large, dense core vesicles (dcv).

Proximal (1.0-1.4 $\mu \mathrm{m}$ diameter) and distal $(0.4-0.6 \mu \mathrm{m} \mathrm{di-}$ ameter) dendrites comprised only $14 \%$ (88 out of 625 ) of all the TH-I profiles. The dendrites contained the usual cytoplasmic organelles, including mitochondria, ribosomes, and microtubules. The labeled dendrites were most often postsynaptic to 1 unlabeled terminal seen in a single plane of section (Fig. $2 A$ ). The unlabeled terminals measured 0.4-1.2 $\mu \mathrm{m}$, contained mitochondria and numerous flattened or oval scv's, and appeared to form primarily asymmetric densities.

Axons and axon terminals with TH-I comprised the remaining $83 \%$ (524 out of 625 ) of all labeled profiles in the dorsal, ventral, central, and external nuclei of the PBR. The axons were primarily small $(0.1-0.2 \mu \mathrm{m}$ in diameter) and unmyelinated (Fig. $4 A)$. However, occasionally a slightly larger $(0.3-0.5 \mu \mathrm{m}$ in diameter), lightly myelinated axon also showed peroxidase immunoreactivity (Fig. 2C). Both myelinated and unmyelinated axons with TH-I were found within groups of other labeled and unlabeled axons and terminals (Figs. $2 C, 4 A, 5 C$ ).

At least 2 types of TH-I terminals were morphologically distinguishable. These 2 types are described separately as they appear in micrographs of single sections; however, they may represent different planes of section through a common terminal. The first type was small $(0.3-0.6 \mu \mathrm{m})$ and contained a relatively homogeneous population of round scv's. These terminals were directly apposed to other unlabeled axon terminals and dendrites but usually lacked clearly defined membrane specializations (Fig. 2, B, C). Functional relationships between the apposed neuronal processes were suggested by their glial isolation from both the surrounding neuropil and from nearby blood vessels (Fig. 2B). A few of the smaller terminals also formed both symmetric (Fig. 5C) and asymmetric (Fig. 4A) synapses with unlabeled dendrites. The second type of terminal measured $0.8-1.4 \mu \mathrm{m}$ in cross-sectional diameter, contained numerous scv's $(25-50 \mathrm{~nm})$, and also from 3 to 6 large $(80-120 \mathrm{~nm})$ dcv's and several mitochondria. These terminals primarily formed symmetric synapses with unlabeled perikarya or proximal dendritcs (Fig. 3) or asymmetric synapses with more distal unlabeled dendrites and dendritic spines (Fig. $4, B, C$ ). In most cases, the TH-I terminals of types I or II formed synapses with unlabeled dendrites that also received contacts from other unlabeled terminals in the same plane (Fig. $5 A$ ). However, in other examples 2 labeled terminals with similar (Fig. $5 C$ ) or different (Fig. 5B) morphological appearances terminated on a common unlabeled dendrite. In addition, terminals with characteristics of both types I and II formed synapses with perikarya and dendrites containing TH-I (Fig. 6). When both profiles were labeled the synaptic specializations were frequently obscured by the peroxidase immunoreactivity (Fig. $6, A, B$ ). However, dense pre- and postsynaptic membranes were sometimes detectable at the region of apposition (Fig. $6 \mathrm{C}$ ). The $2 \mathrm{TH}-\mathrm{I}$ profiles were separated from the surrounding neuropil and from neighboring blood vessels by thin astrocytic processes (Fig. 6, $A-C$ ).

\section{HRP histochemistry alone or in combination with immunocytochemistry}

Restricted central injections of the PBR with WGA-HRP resulted in retrogradely labeled perikarya in multiple brain-stem and diencephalic regions. The relative distribution of retrogradely labeled perikarya was dependent upon the location of the injection site as well as the amount of WGA-HRP injected, but appeared to be unaltered by the colchicine treatment or by the dual processing for transport and immunocytochemistry.

\section{Injection sites}

The most consistent number of retrogradely labeled neurons was seen following $30 \mathrm{nl}$ injections of 10\% WGA-HRP which were centered in the midrostrocaudal level of the PBR. A dense region of peroxidase reaction product surrounded the area of the tissue that had contained the tip of the micropipette. This dense central zone of labeling in the PBR was enclosed in a much larger diffusion sphere, which was exaggerated by the sensitivity of the TMB reaction (Figs. 7,8). A total of 9 animals processed only for retrograde transport of WGA-HRP had injections centered in the PBR. In these animals, the dense granular reaction product for retrogradely transported WGA-HRP was detected in perikarya located in the medulla oblongata, pons, and diencephalon. These regions correspond to the known afferents to the PBR (Hopkins and Holstege, 1978; Loewy and Burton, 1978; Norgren, 1978; Saper et al., 1979; Swanson, 1982). Thus, the results of WGA-HRP transport alone will not be presented. In 7 additional animals, the injections were centered within structures adjacent to the PBR. Injections centered within the principal sensory and motor trigeminal nuclei ( 5 animals), the ventral spinal cerebellar tract (1 animal), and the lateral lemniscal nuclei (1 animal) did not produce retrogradely labeled perikarya in the same regions as those seen following injections centered in the PBR, even though the diffusion spheres overlapped in many areas. It is possible that the diffusion sphere of injections centered in the PBR may have included a few neurons in the locus coeruleus. However, in all cases the effective injection for labeling afferents to the PBR was considered to be the central zone exclusive of the diffusion sphere, since others have shown that the diffusion sphere contributes little, if any, to the transport (Ruggiero et al., 1982).

\section{Distribution of labeled neurons}

In animals processed for the dual localization of retrogradely transported WGA-HRP and immunocytochemical detection of the TH, 8 of the injections were centered in the morphological boundaries of the PBR (using the criteria described above for the distinction between the central zone and diffusion sphere). Figure $8 A$ represents 1 case (rat 43084 ) with such an injection.

In these dual-labeling experiments, the black granular reaction product formed by cobalt intensification and DAB stabilization of the TMB reaction for WGA-HRP was readily distinguishable from the brown PAP reaction product for TH (see Fig. 11). The distributions of perikarya containing only retrogradely transported WGA-HRP, only TH-I, or both markers, were identified in the medulla oblongata, pons, mesencephalon, and diencephalon. The intensity of the perikaryal labeling for $\mathrm{TH}$ was enhanced in animals pretreated with colchicine as compared to normal rats. However, the distribution of the labeled cells was equivalent in both groups. The location of the perikarya with TH-I in the dual-labeling study was identical to that seen when the sections were processed exclusively for immunocytochemistry. The location of perikarya was designated as ipsi- or contralateral with respect to the parabrachial injection. 

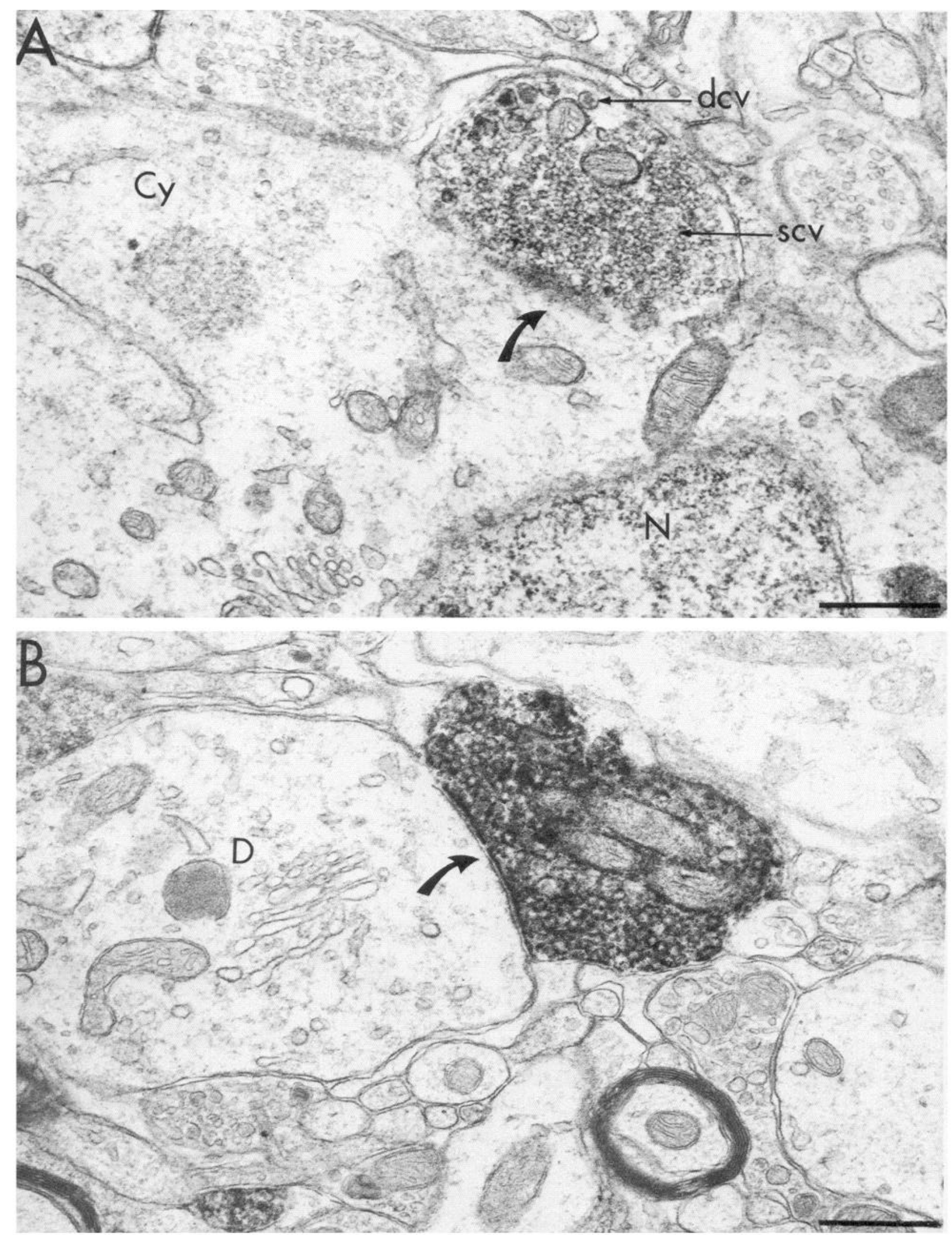

Figure 3. Single axosomatic and axodendritic associations of terminals with TH-I. The labeled terminals contain many small clear vesicles (scv) and a few dense core vesicles $(\mathrm{dcv})$. $A$, Type II labeled terminal forms a symmetric synapse (solid arrow) on an unlabeled perikarya. B, Type II labeled terminal forms a symmetric synapse with an unlabeled proximal dendrite. Bar, $0.5 \mu \mathrm{m}$. 

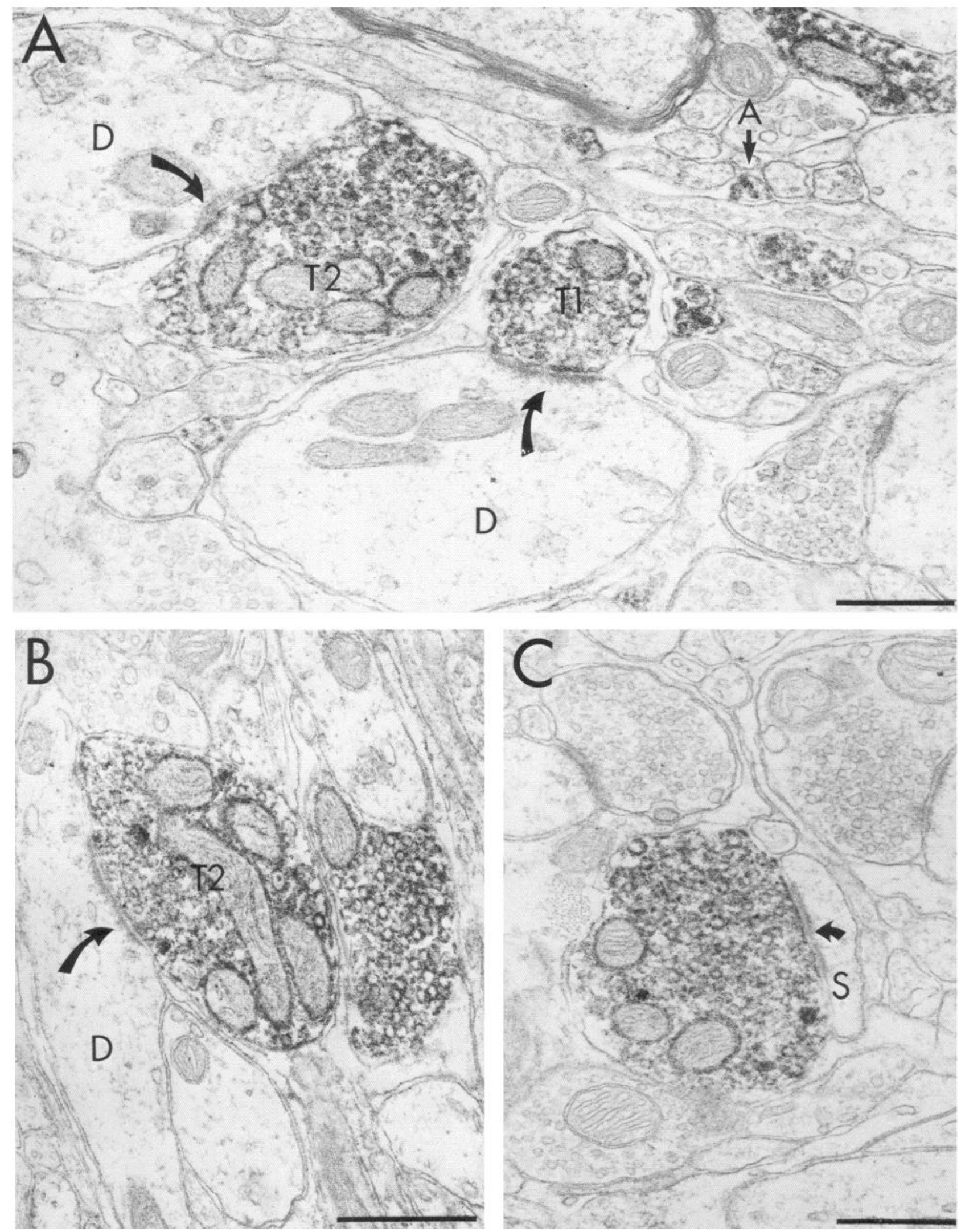

Figure 4. Single axodendritic associations of TH-I terminals within the lateral PBR. $A$ and $B$, Both type I (TI) and type II (T2) labeled terminals form asymmetric synapses (solid arrows) with separate unlabeled dendrites $(D)$. $C$, Type II labeled terminal forms an asymmetric synapse (solid arrow) on a dendritic spine $(S)$. Bars, $0.5 \mu \mathrm{m}$. 

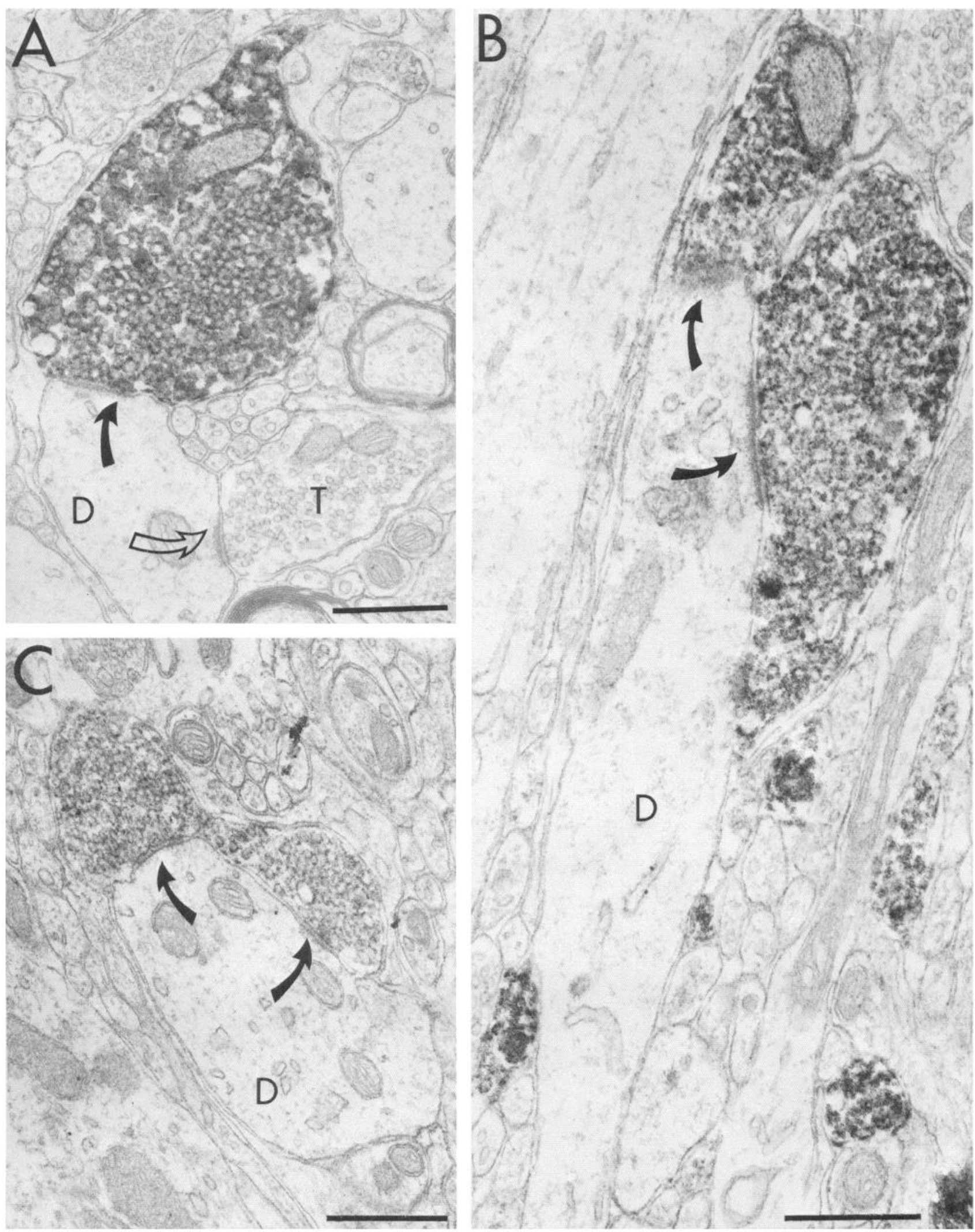

Figure 5. Axodendritic associations of terminals with TH-I in the lateral PBR. A, Both a labeled type II and an unlabeled terminal form asymmetric synapses (solid and open arrow, respectively; $T$ ) on an unlabeled dendrite $(D)$. B. Two type II labeled terminals (solid arrows) form asymmetric synapses on a common dendrite $(D)$. $C$, Two type I labeled terminals form symmetric synapses (solid arrows) on a common dendrite $(D)$. Bars, $0.5 \mu \mathrm{m}$. 

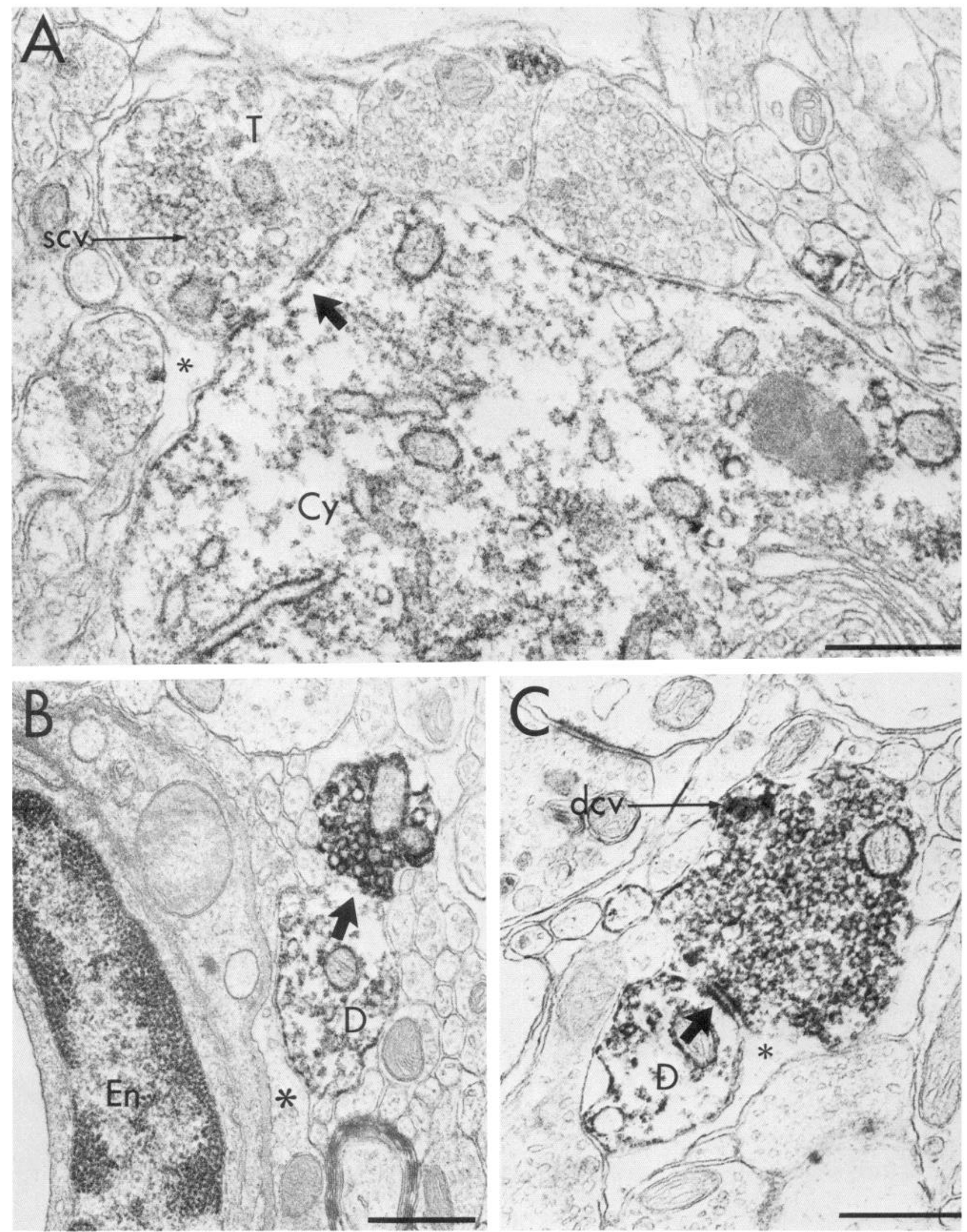

Figure 6. Associations of TH-I terminals with TH-labeled perikarya and dendrites. A, Portions of the plasma membrane of a TH-I soma receive a contact (solid arrow) from a labeled type II axon terminal $(T)$, which contains many small clear vesicles (scv). In this plane of section, the terminal with TH-I appears to form a symmetric junction or to lack an observable density. $B$, TH-labeled type I terminal contacts (arrow) a TH-I dendrite $(D)$. The labeled dendrite was isolated from the neighboring blood vessel by a thin astrocytic process (*). En, Endothelial cell of blood vessel. $C$, An axodendritic junction with a clearly differentiated synaptic density (solid arrow) is seen between a type II labeled terminal and a labeled dendrite $(D)$. The labeled terminal contains many small clear vesicles and a few dense core vesicles $(d c v)$. In both $A$ and $C$, the labeled processes are separated from the surrounding neuropil by an astrocytic process (*). Bar, $0.5 \mu \mathrm{m}$. 

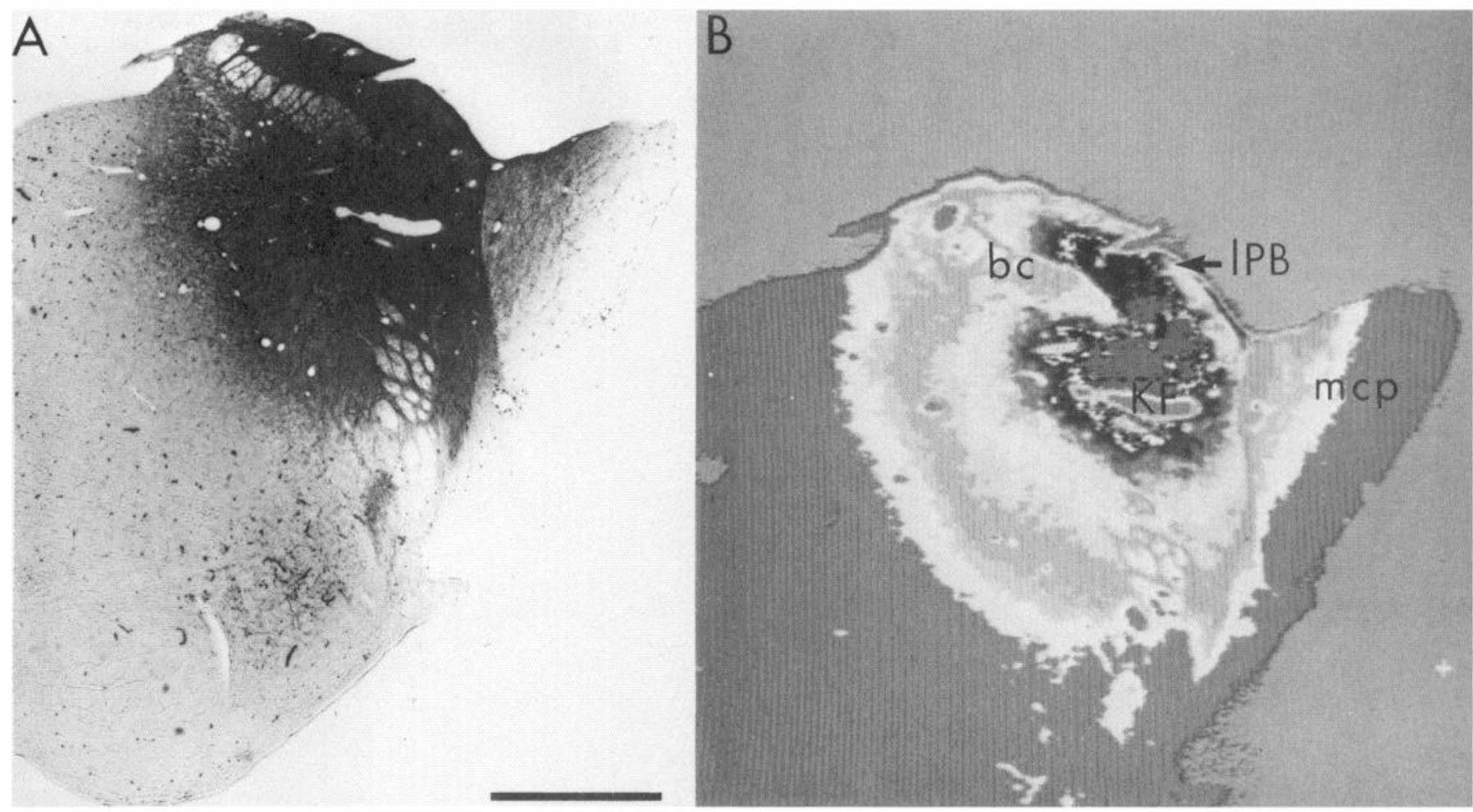

Figure 7. Injection site in pons of animal dually processed for WGA-HRP transport and TH-I. $A$, Low-magnification photomicrograph shows that the injection site is centered in the lateral PBR and Kölliker Fuse nucleus. The injection appears large since the tissue was first reacted with TMB, stabilized with DAB, and intensified with cobalt. $B$, Computer image of the injection site shows the clear distinction between the smaller, dense central zone of the injection (black) and the larger diffusion sphere (whites and grays). Bar, $1 \mathrm{~mm}$.

Medulla oblongata. In the medulla oblongata (Fig. 9), retrogradely transported WGA-HRP was found bilaterally in neuronal perikarya: (1) in the NTS predominantly in the dorsal, medial, and commissural aspects; (2) in the area postrema; (3) in the parvicellular reticular formation; and (4) in the rostral and caudal ventrolateral medulla. With the exception of the parvicellular reticular formation, TH-I perikarya were bilaterally distributed in all of the same regions as cells projecting to the PBR (Fig. 9). Dual labeling for retrogradely transported WGA-HRP and TH-I was detected primarily within perikarya in the medial and commissural NTS and in the caudal and rostral ventrolateral medulla. These nuclei are known to contain the principally noradrenergic neurons of the $\mathrm{A} 2$ and $\mathrm{A} 1$ groups (Dählström and Fuxe, 1964) and the adrenergic neurons of the C1 and C2 groups (Hökfelt et al., 1974), respectively. A few perikarya containing both labels were also found in the area postrema. These cells were ipsilateral to the WGA-HRP injection (Fig. 9, $A-G$; see also Fig. 11, $A-E$ ).

Pons. In the dorsolateral pons (Fig. 8), cells containing only WGA-HRP were found: (1) in the raphe pontis and dorsalis; (2) bilaterally in the locus coeruleus and subcoeruleus; (3) in the ipsilateral lateral dorsal tegmental nucleus; (4) in the ipsilateral mesencephalic and motor trigeminal nuclei; and (5) in the ipsilateral reticular formation, near the A5 group of catecholaminergic neurons (Dählström and Fuxe, 1964). The perikarya containing TH-I were concentrated in the locus coeruleus and subcoeruleus, the lateral PBR and Kölliker Fuse nuclei, and the ventrolateral pons. The latter regions contain the A5 and A7 groups of catecholaminergic neurons (Dählström and Fuxe, 1964). Of these regions, only the locus coeruleus ipsilateral to the injection contained substantial numbers of perikarya with both retrogradely transported WGA-HRP and TH-I. However, the contralateral locus coeruleus and ipsilateral $\mathrm{A} 5$ region also contained a few cells with colocalization of the 2 markers (Figs. $8,11 F)$.

Mesencephalon. In the mesencephalon, cells containing only WGA-HRP were found: (1) in the ventral tegmental area ipsilateral to the injection; (2) in the paramedian interpeduncular nucleus, ipsilaterally; and (3) in the central linear nucleus. Perikarya containing TH-I were found in the ventral tegmental area and substantia nigra, corresponding to the $\mathrm{A} 9$ and $\mathrm{A} 10$ cell groups of Dählström and Fuxe (1964). No dual-labeled neurons were seen in any other other portion of the mesencephalon.

Diencephalon and telencephalon. In the diencephalon (Fig. 10 ), retrogradely labeled perikarya were located ipsilaterally in the paraventricular, dorsomedial, and lateral hypothalamic nuclei. In the telencephalon, retrogradely labeled neurons were found in the central amygdaloid nucleus. The neuronal perikarya showing TH-I were found largely in the paraventricular, periventricular, and arcuate hypothalamic nuclei, corresponding to the A11-A14 cell groups of Dählström and Fuxe (1964) (Fig. 10). Dual labeling of retrogradely transported WGA-HRP and TH-I was largely restricted to the paraventricular hypothalamic nucleus (Fig. 10). These cells were ipsilateral to the injection and were few in number.

\section{Discussion}

The results of this study provide a number of new findings relevant to the anatomical and functional relationships of catecholaminergic neurons in the adult rat PBR. These include (1) TH-I perikarya differ in their ultrastructural morphology, location, and relative numbers of somatic synapses; (2) catecholaminergic (TH-I) neurons receive synaptic input from catecholaminergic (TH-I) terminals and from terminals that lack detectable immunoreactivity; (3) TH-I is found in both myelinated and unmyelinated axons; (4) the principal localization 

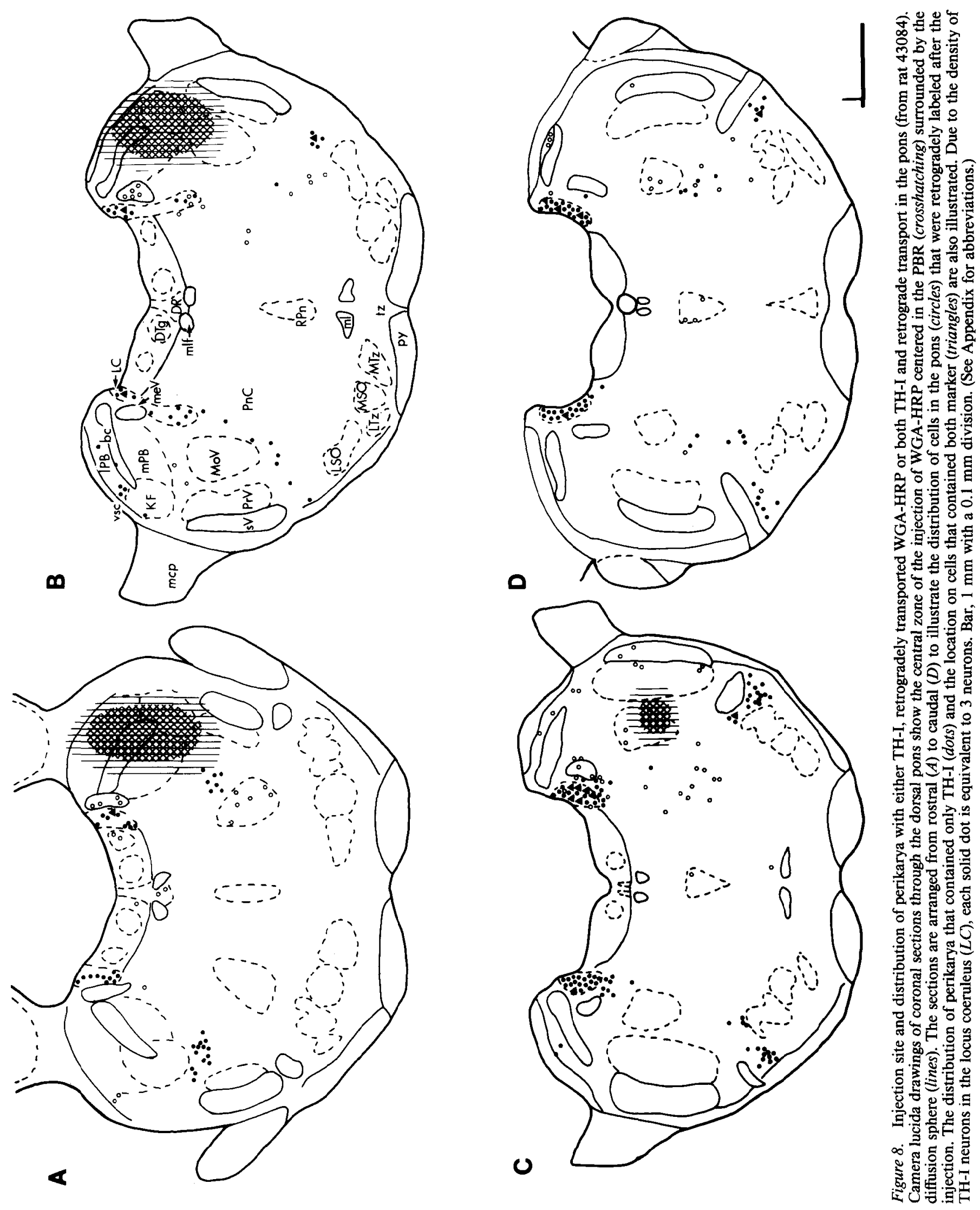

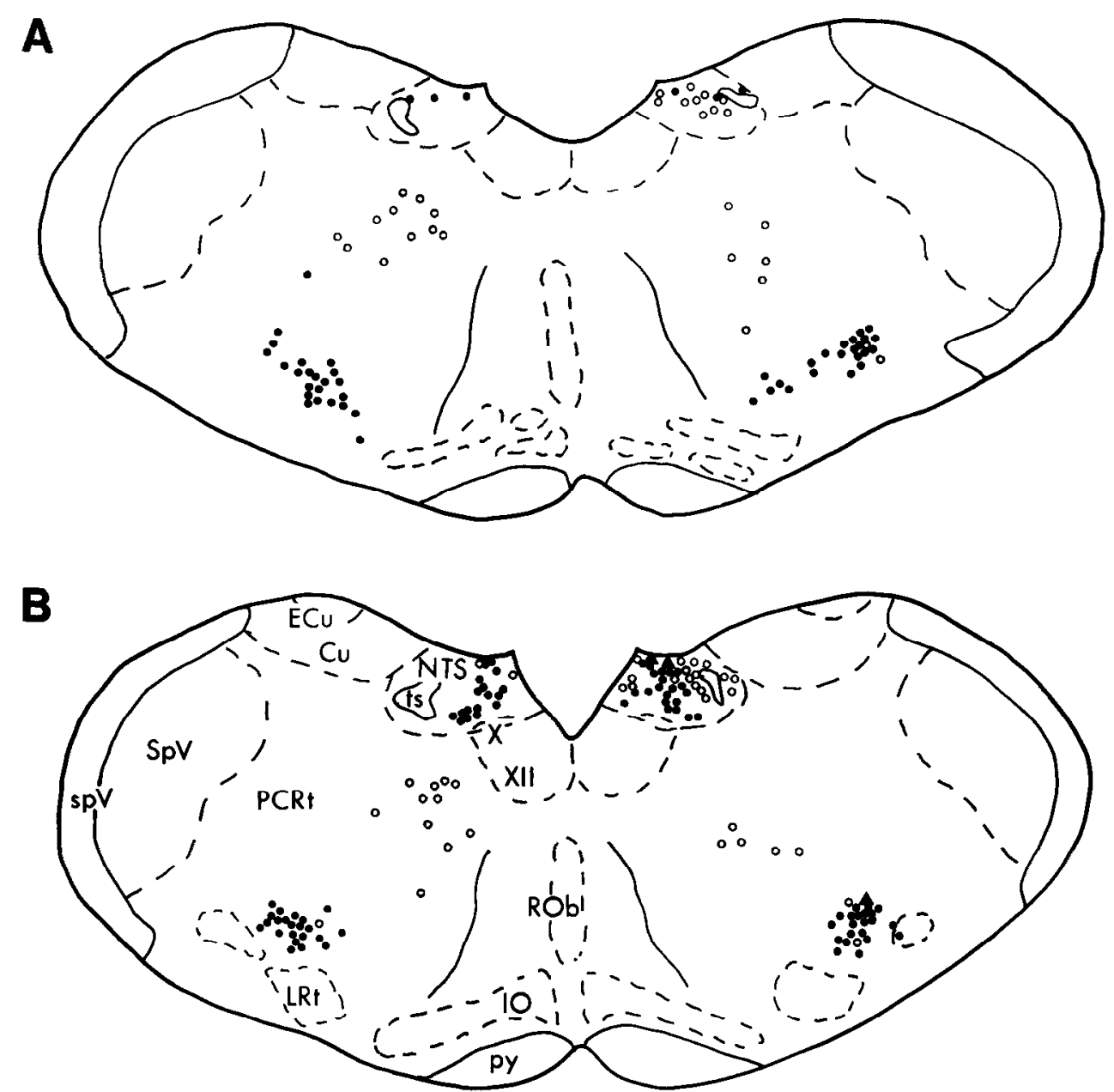

Figure 9. Camera lucida drawings of coronal sections arranged from rostral $(A)$ to caudal $(G)$ through the medulla oblongata (of rat 43084) show the distribution of neurons that contain retrogradely transported WGAHRP (circles) following the injection shown in Figure 8, the distribution of cells containing only TH-I (dots), and the distribution of dually labeled neurons (triangles). Bar, $1 \mathrm{~mm}$ with a 0.1 $\mathrm{mm}$ division. (See Appendix for abbreviations.)

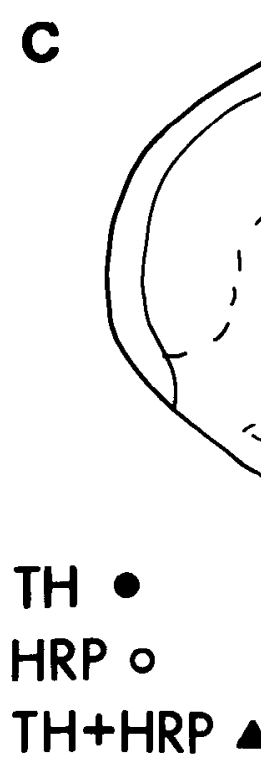

of TH is in axon terminals with morphological and labeling properties similar to those of dopaminergic neurons that exhibit both symmetric, asymmetric, and apparently nonsynaptic junctions; and (5) cell groups of the brain stem, pons, and diencephalon including noradrenergic, adrenergic, and possibly dopaminergic neurons contribute efferents to the PBR.
Morphologic distinction of perikarya into two types

The intensity of the immunoreactivity, large size, and abundant cytoplasmic organelles suggest that the type I neuron found in the dorsal and ventral lateral nuclei is highly metabolically active. Similar properties have been described for dopaminergic 
D

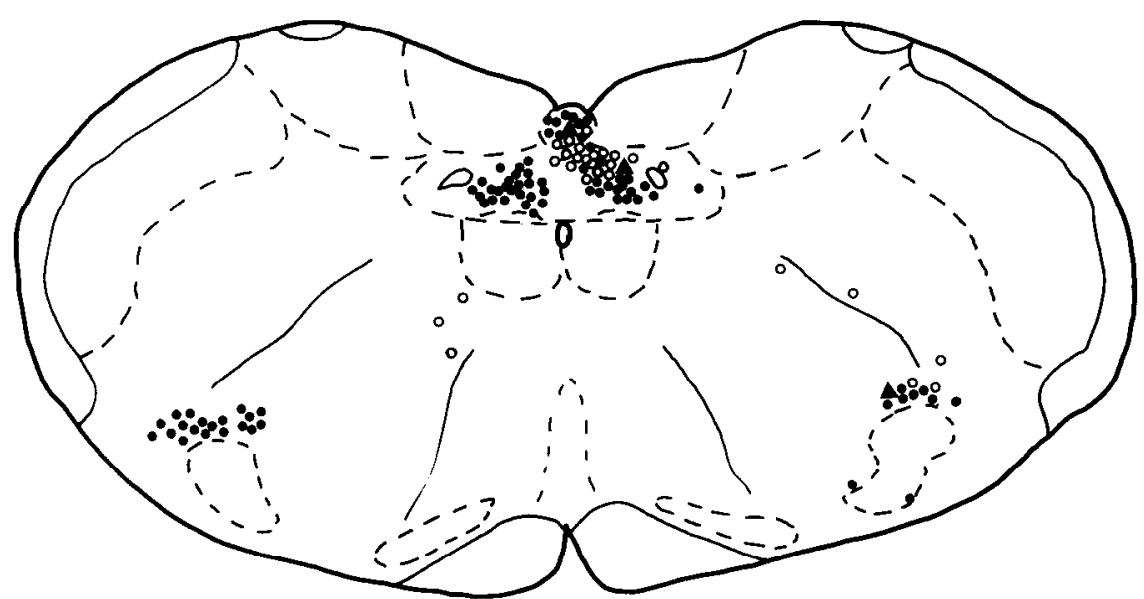

E

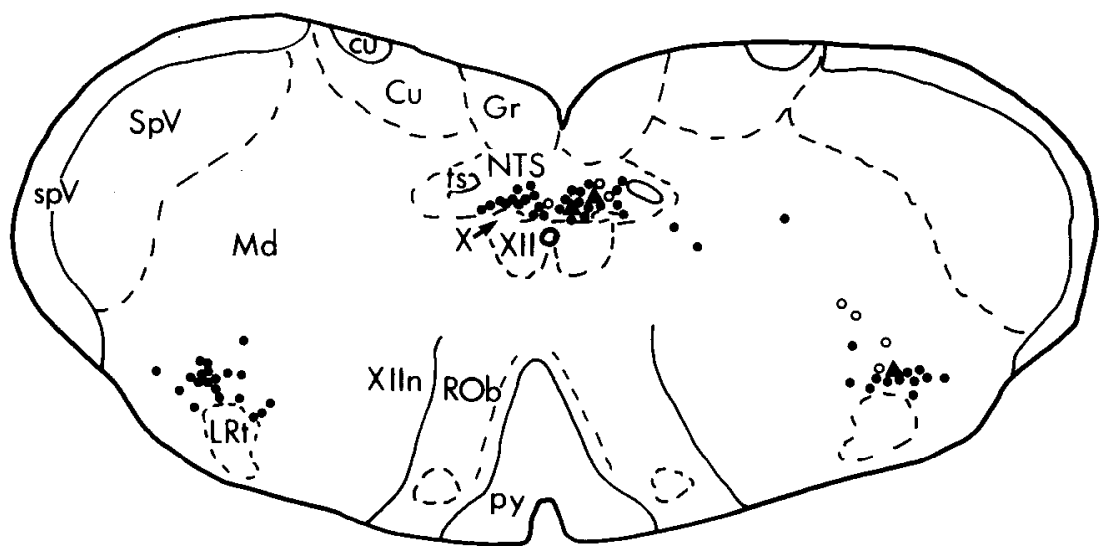

F

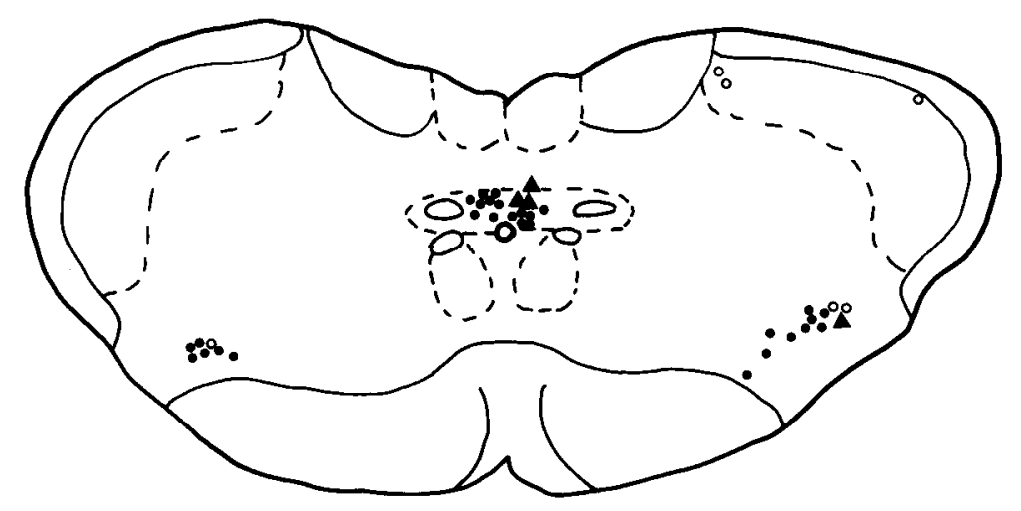

G

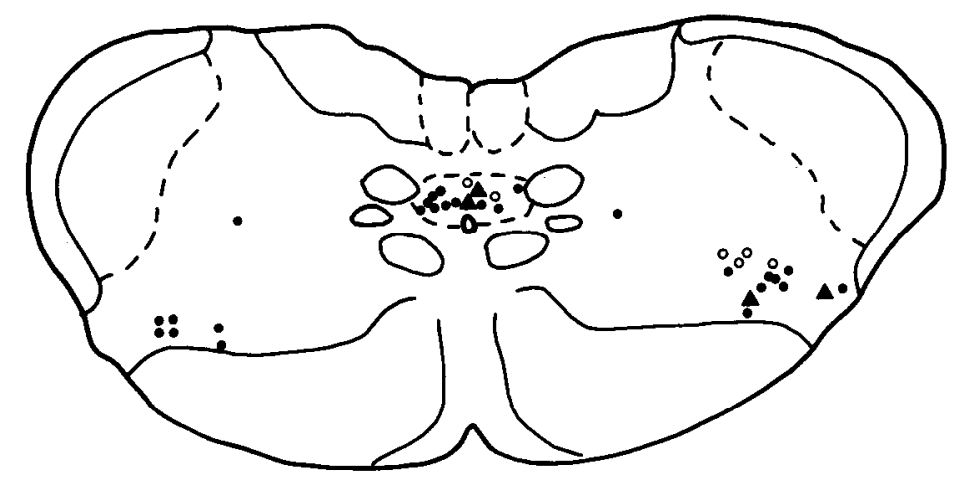


A

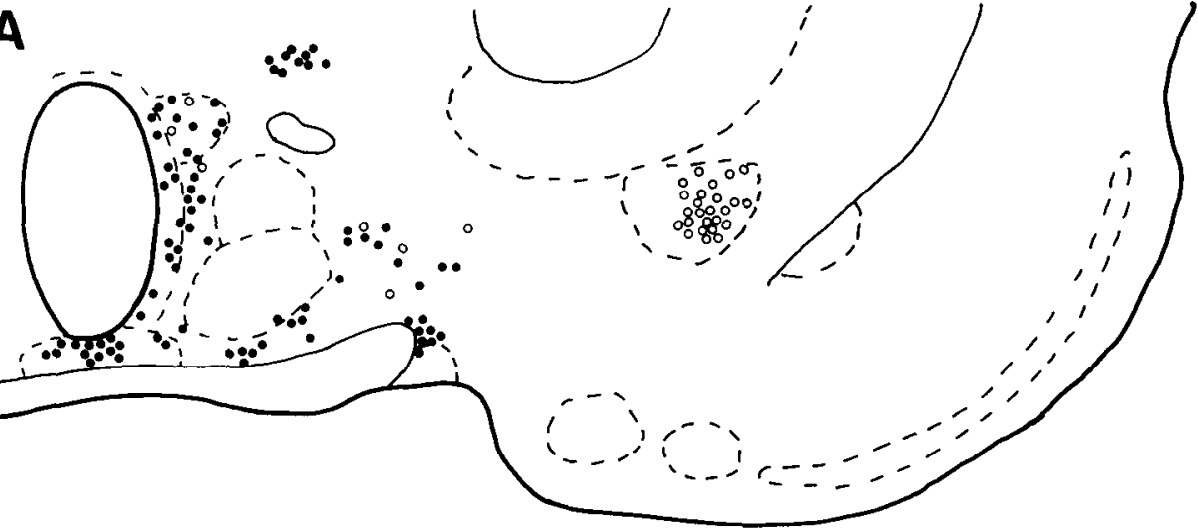

B
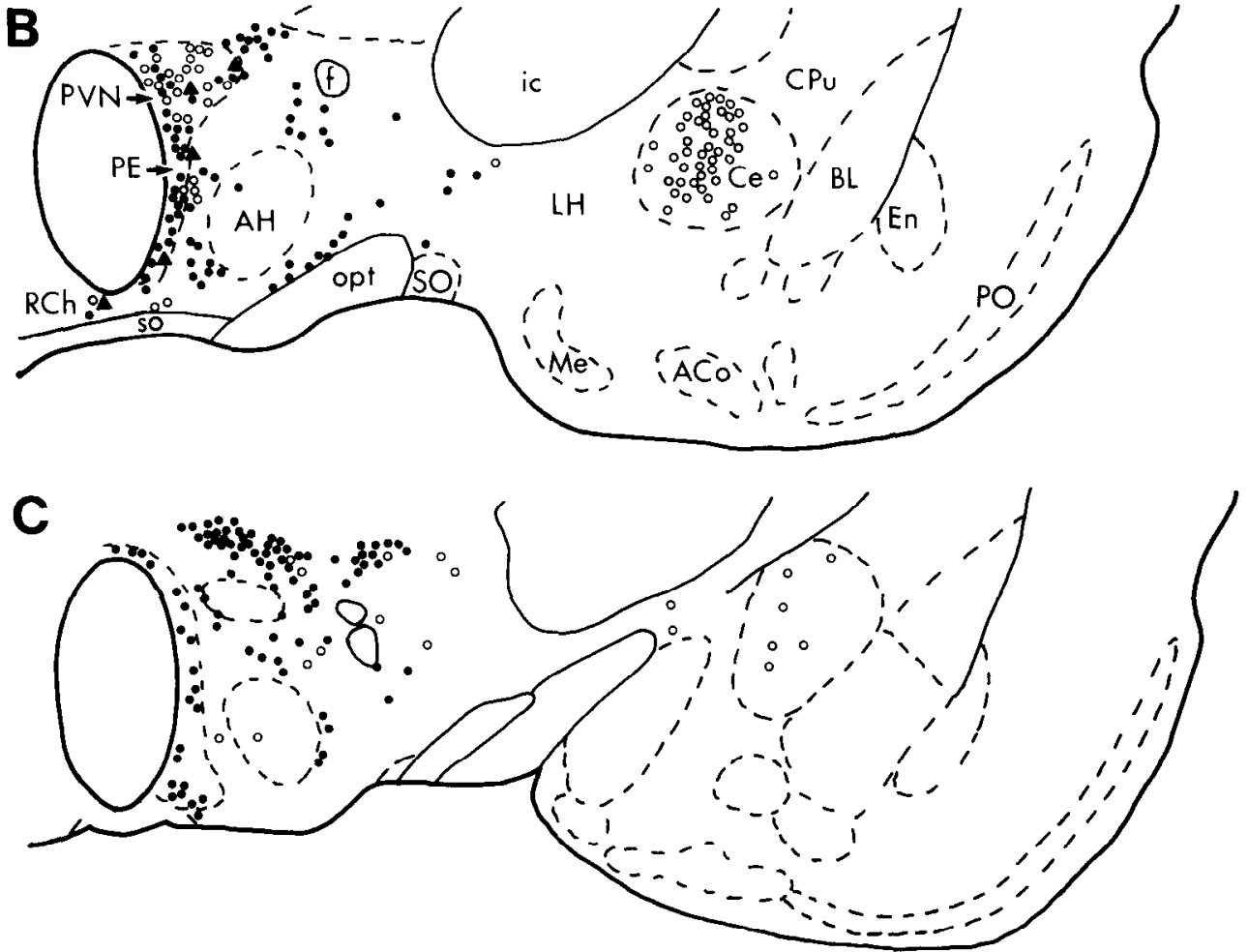

D

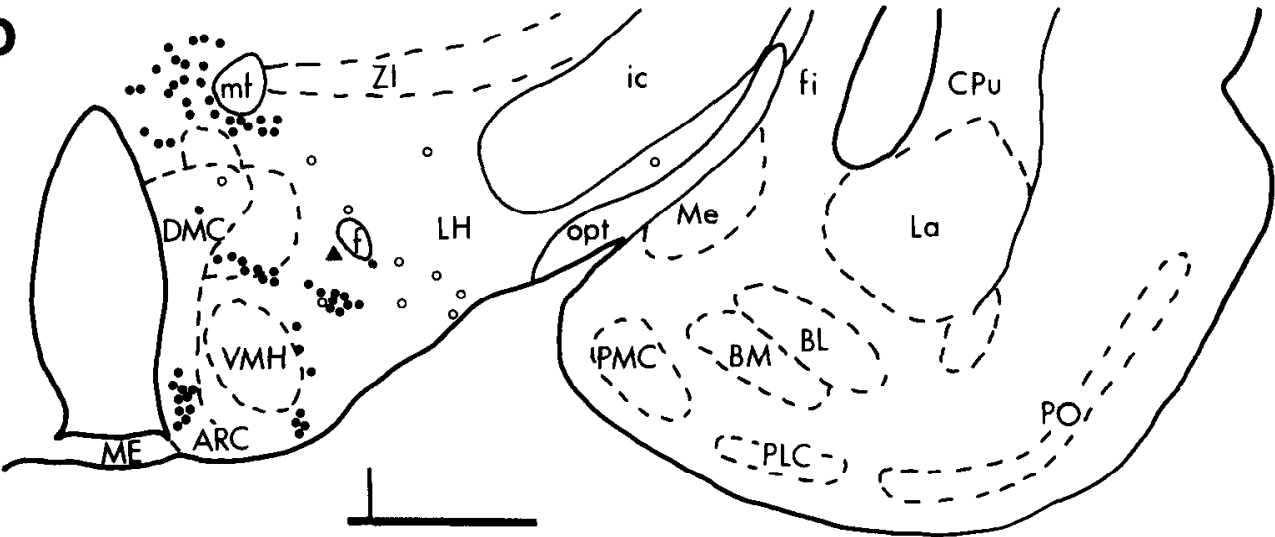

Figure 10. Camera lucida drawings of coronal sections (from rat 43084 ), arranged from rostral $(A)$ to caudal $(D)$ through the hypothalamus and amygdala ipsilateral to the injection shown in Figure 8, show the distribution of cells that contain only retrogradely transported WGA-HRP (circles), TH-I alone (dots), or both markers (triangles). Bar, $1 \mathrm{~mm}$ with a $0.1 \mathrm{~mm}$ division. (See Appendix for abbreviations.)

Figure 11. Photomicrographs show perikarya that contain only TH-I (brown reaction product), only retrogradely transported WGA-HRP (black granular reaction product), or both TH-I and the retrogradely transported WGA-HRP (brown and black granular reaction product) in 3 different areas of the brain. $A$ and $B$, Photomicrographs of perikarya in the NTS that contain only TH-I (brown cells), only retrogradely transported WGAHRP $(A$, open arrow), or bolh labels $(C-E$, closed arrows). Photomicrographs of perikarya in the rostroventrolateral medulla that contain only TH-I (brown product) or retrogradely transported WGA-HRP $(E$, open arrow) or both reaction products $(C$, closed arrow). $F$, Low-magnification 

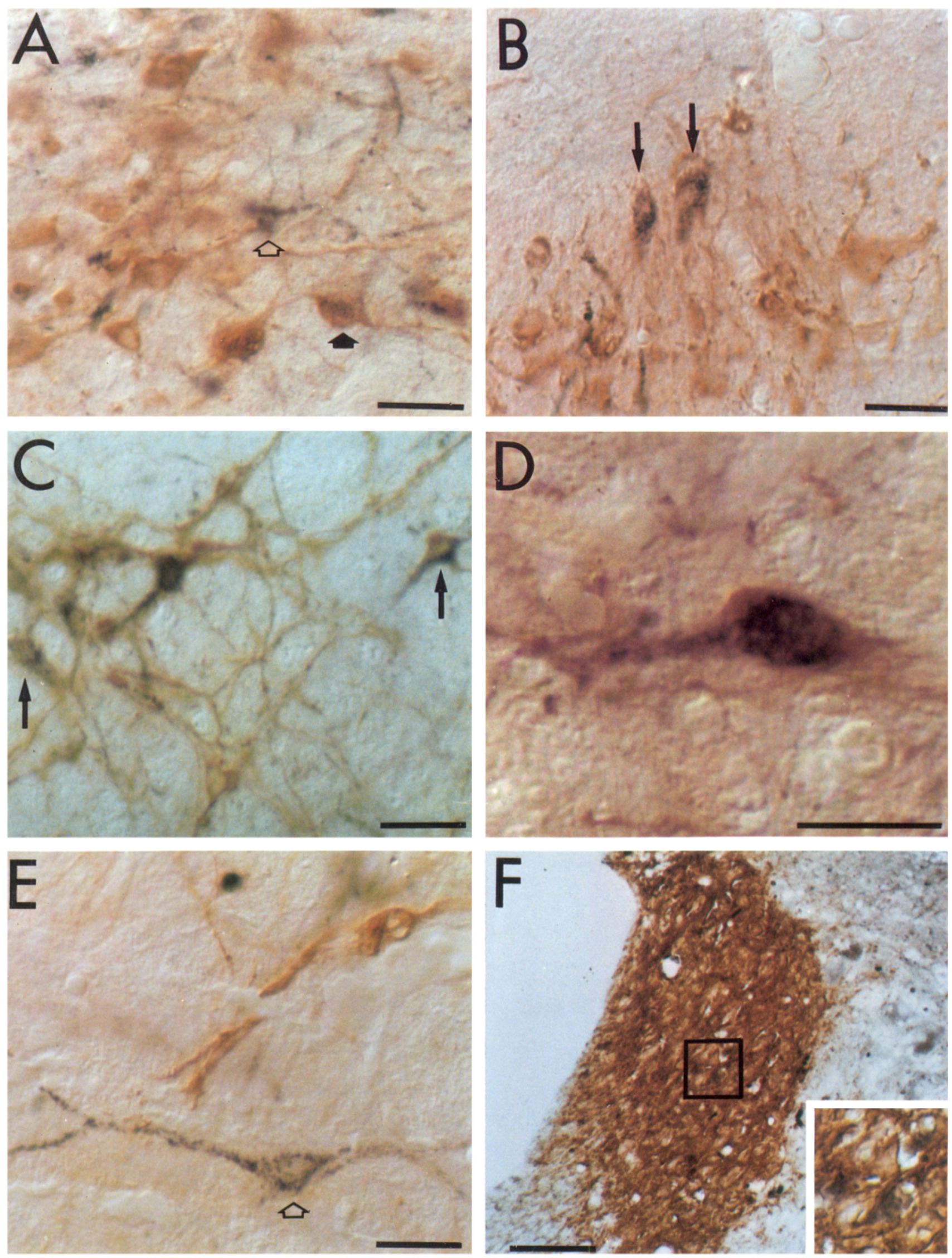

photomicrograph of the locus coeruleus shows numerous perikarya that contain only TH-I or both reaction products. Boxed area is enlarged in lower right-hand corner to show 3 doubly labeled neurons. Bar, $25 \mu \mathrm{m}(A-E) ; 100 \mu \mathrm{m}(F)$. 
neurons of the substantia nigra (Bak, 1967; Schwyn and Fox, 1974), noradrenergic neurons of the locus coeruleus (Cimarusti et al., 1979; Pickel et al., 1975), and adrenergic neurons of the rostral ventrolateral medulla (Milner et al., 1985). The high level of metabolic activity in catecholaminergic neurons may reflect their large terminal fields, high production of catecholamines, or production of other coincident enzymes or peptides (Everitt et al., 1984; Hökfelt et al., 1980).

The second type of perikarya containing TH-I was distinguished not only by their location in the central lateral nucleus of the PBR, but also by their smaller size, heavily indented nuclei, and more abundant somatic synapses. These features are common to medium-sized spiny neurons, which have been shown in regions such as the striatum to give rise both to local axon collaterals and to efferent axons (Bolam et al., 1981). The intrinsic $\mathrm{TH}$-containing neurons thus may account for at least a few of the TH-labeled terminals in the PBR. However, the small number of labeled perikarya in both normal and colchicine-treated rats suggests that other afferents probably contribute extensively to the observed immunoreactive terminals.

\section{Synaptic input to TH-I neurons}

The presence of synapses from both TH-labeled and unlabeled terminals on the soma of type II neurons containing TH-I suggests a powerful modulatory input from both catecholaminergic and noncatecholaminergic neurons. The catecholaminergic synapses could provide an anatomical basis for the marked inhibition of noradrenergic and dopaminergic neurons produced by local administration of the respective transmitters (Bunney et al., 1973; Svensson et al., 1975). However, since TH is a common synthesizing enzyme for all catecholaminergic neurons, the synaptic associations also could reflect interactions between different monoamines such as dopamine and norepinephrine. In addition to the catecholaminergic inputs, afferents from the amygdala and lateral hypothalamus, which contain few, if any, TH-labeled perikarya, form axosomatic synapses with neurons similar to the type II neurons of the present study (Takeuchi and Hopkins, 1984; Takeuchi et al., 1982). These investigators did not identify the recipient neurons as catecholaminergic. Thus, additional studies are necessary to establish definitively whether these pathways terminate on the catecholaminergic neurons.

The dendrites with $\mathrm{TH}$-I principally received input from unlabeled terminals. The possible transmitter(s) in these unlabeled terminals may include enkephalin or GABA, both of which are found in abundance within terminals in the PBR and are known to form synapses with catecholaminergic dendrites in other areas (Pickel et al., 1984, 1986). The only transmitters of more definitive identity in terminals forming contacts with the THlabeled dendrites are the catecholamines, as shown by comparable immunoreactivity for the enzyme in both the pre- and postsynaptic profiles. As discussed with respect to the axosomatic synapses between $2 \mathrm{TH}$-labeled profiles, these junctions may reflect the same or different catecholamines.

\section{Localization in myelinated and unmyelinated axons}

Axons showing TH-I were either small and unmyelinated or slightly larger with several layers of myelin. The unmyelinated axons are comparable to the noradrenergic and dopaminergic axons found in most other regions of the CNS (Pickel et al., 1976, 1981). At least some of the neurons of noradrenergic cell groups in the dorsolateral pontine tegmentum, including the PBR, project to the spinal cord (Westlund et al., 1983). The myelination or lack of myelination could influence the conduction velocities of these axons to the spinal cord, as has been proposed for other catecholaminergic cell groups in the medulla that similarly project to the spinal cord (Brown and Guyenet, 1984).

\section{TH-I in terminals with dopaminergic morphology}

The occurrence of 2 principal types of axon terminals containing TH in the lateral PBR corresponds remarkably well with the localization of the enzyme within dopaminergic terminals in the striatum and nucleus accumbens (Bouyer et al., 1984; Pickel et al., 1981). The smaller type I terminal that forms nonspecialized junctions and both symmetric and asymmetric synapses with unlabeled dendrites and axon terminals is morphologically analogous to the dopaminergic terminals in the striatum (Descarries et al., 1980; Pickel et al., 1981); whereas the second or larger type of terminal containing several large dcv's is more comparable to the dopaminergic terminals of the nucleus accumbens (Bouyer et al., 1984). The existence of greater numbers of dcv's in the mesolimbic pathway from the ventral tegmental area to the nucleus accumbens is believed to reflect the coexistence of cholycystokinin within the dopaminergic neurons (Hökfelt et al., 1980). Conceivably, the second type of terminal in the present study may contain dopamine as well as a coexisting peptide or another catecholamine (Hökfelt et al., 1984a).

\section{Afferent sources of $\mathrm{TH}$}

The results of the single-labeling immunocytochemical study confirm carlicr rcports on the localization of the catecholamines and their synthetic enzymes, $\mathrm{DBH}$ and $\mathrm{TH}$, in perikarya of rat brain (Dählström and Fuxe, 1964; Palkovits and Jacobowitz, 1974; Swanson and Hartman, 1975). The single labeling for retrograde transport of WGA-HRP similarly confirms earlier studies showing that most of the ncurons projecting to the PBR are found bilaterally in the NTS and the ventrolateral medulla (King, 1980; Loewy and Burton, 1978; Norgren, 1978; Ricardo and Koh, 1978); the ventral tegmental area (Swanson, 1982); the paraventricular, dorsomedial, and lateral hypothalamic nuclei (Saper et al., 1979; Sawchenko and Swanson, 1982); and the central nucleus of the amygdala (Hopkins and Holstege, 1978).

The similarities in numbers of immunoreactive and retrogradely labeled neurons in single- or dual-labeling studies indicate that the combined methods used in this study are highly applicable for determining the putative transmitters within pathways of the CNS. The dual-labeling method was initially used for large cholinergic neurons of the nucleus basalis (Wainer and Rye, 1984). More recently we have utilized similar methods to demonstrate that substance $P$ and neurotensin are contained in afferent pathways to the PBR (Milner and Pickel, 1986a, b). Thus, the dual-labeling technique is applicable to large as well as small neurons containing a variety of putative transmitters. If, as is the case with certain catecholamine synthesizing enzymes (Ruggiero et al., 1985) and neuropeptides (Ljungdahl et al., 1978), the immunoreactivity is poorly detectable without pretreatment of the animal with colchicine, our findings indicate that moderate doses of the drug can be used with experimentally controlled conditions. In the present report and in 2 earlier ones (Milner and Pickel, 1986a, b), we have demonstrated the feasibility of intraventricular injections of colchicine a day after placement of WGA-HRP into the PBR and a day prior to sacrifice. Different doses of colchicine or various survival times may be required for other transmitters or other regions of the brain.

The dual-labeling study further supports the existence of a catecholaminergic pathway from the m-NTS to the PBR (Mantyh and Hunt, 1984) and additionally establishes that catecholaminergic neurons in the commissural NTS, area postrema, ventrolateral medulla, pontine neurons of the locus coeruleus and A5 cell group, and paraventricular hypothalamic nuclei also project to the PBR. The projection from the NTS or A2 cell group of Dählström and Fuxe (1964) appears to be one of the major catecholaminergic pathways to the PBR, since we de- 
tected more dually labeled cells in this area than in any other regions of the brain. The concentration of retrogradely labeled catecholaminergic neurons in the caudal, medial, and commissural portions of the NTS further suggests that they may be an important neuroanatomical link in the cardiovascular pathways to the forebrain (Loewy and McKellar, 1980). The termination of vagal afferents on catecholaminergic neurons of the m-NTS has recently been shown by combined immunocytochemistry for TH and anterograde transport of tritiated amino acids from the nodose ganglion (Suma' et al., 1983). The catecholaminergic neurons from the NTS or A2 group also project to the paraventricular nuclei of the hypothalamus (Sawchenko and Swanson, 1982), suggesting that there are at least 2 parallel pathways whereby the catecholaminergic neurons in the NTS transmit information to more rostral integrative centers.

The catecholaminergic projection from the area postrema to the PBR may similarly be involved in conveying information regarding changes in the internal (humoral or visceral) environment (Borison, 1974; Ferrario et al., 1979). The catecholaminergic neurons in the area postrema are directly apposed to the surface of intrinsic blood vessels (Armstrong et al., 1982a; Pickel and Armstrong, 1984). These vessels lack the usual brain capillary barriers (Brightman and Reese, 1975) and thus provide access of circulating hormones such as angiotensin II to the intrinsic blood vessels. Furthermore, the catecholaminergic neurons in the area postrema, like those in the m-NTS, receive direct synaptic input from neurons in the nodose ganglia (Pickel et al., 1983). Thus, the present demonstration of the efferent projection of the catecholaminergic neurons in the area postrema to the PBR suggests one convergent pathway conveying changes in humoral or visceral sensory receptors.

The present localization of both TH-I and retrogradely transported WGA-HRP labeling in the $\mathrm{Al}$ (noradrenergic) and $\mathrm{Cl}$ (adrenergic) neurons of the ventrolateral medulla may also reflect convergent information of relevance to the cardiovascular or other autonomic regulatory system (Blessing and Reis, 1982; Granata et al., 1983). In addition to the PBR, Cl neurons also send axons to the intermediolateral cell column of the spinal cord (Ross et al., 1984) and to the hypothalamus (Sawchenko and Swanson, 1982). Thus, collaterals from these same neurons or possibly different neurons in the same region could be of considerable importance in the integration of sympathetic outflow from the spinal cord with neuroendocrine and autonomic responses from hypothalamic nuclei receiving input from the PBR (Saper and Loewy, 1980).

The present demonstration that certain catecholaminergic perikarya in the ipsilateral and contralateral locus coeruleus project to the PBR supports earlier lesion studies (Levitt and Moore, 1979). Though these investigators concluded that a minor part of the catecholaminergic terminals was probably derived from the locus coeruleus, neither the precise location of the cells nor the ipsi- versus contralateral contribution was demonstrated. The catecholaminergic neurons of the locus coeruleus have widely ramified, principally ascending projections to hypothalamic and forebrain sites (Sawchenko and Swanson, 1982; Swanson and Hartman, 1975). Within the brain stem, the projection to PBR and other pontine and medullary sites may have multiple but, at present, largely unknown regulatory functions.

Our demonstration that TH-I cells within the paraventricular nuclei project to the PBR provides a neuroanatomical basis for feedback modulation among the brain stem, PBR, and neuroendocrine areas of the hypothalamus. As previously indicated, the catecholaminergic neurons of the A2 group project to both the paraventricular nuclei and the PBR (Sawchenko and Swanson, 1982). Moreover, the PBR neurons project both to the paraventricular nuclei (Saper and Loewy, 1980) and NTS (Fulwiler and Saper, 1984), and the paraventricular nuclei project to the PBR and the NTS (Saper et al., 1976). Our results suggest that catecholamines are probably present in several of these pathways. However, other transmitters-including peptides such as neurotensin (Milner and Pickel, 1986b), substance P (Milner and Pickel, 1986a), or enkephalin (Mantyh and Hunt, 1984)may also be involved.

Retrogradely transported WGA-HRP from the PBR and TH are principally colocalized within regions containing noradrenergic (A2, A1, A5, and A6) and adrenergic cell groups (Dählström and Fuxe, 1964; Hökfelt et al., 1974). The comparable light-microscopic distributions of $\mathrm{TH}$ and $\mathrm{DBH}$, the enzyme that converts dopamine to norepinephrine (Milner et al., 1984), supports the concept that many, if not all, of the TH-labeled terminals in the PBR produce noradrenaline or adrenaline. This suggestion initially seems incompatible with the finding from our ultrastructural study, which demonstrated a morphological similarity between the TH-labeled terminals of the PBR and dopaminergic terminals in other regions of the brain (Bouyer et al., 1984; Pickel et al., 1981). However, a dopaminergic innervation of the PBR is supported by lesion studies employing 6-hydroxydopamine (Hedreen, 1980) and by the recent demonstration of dopaminergic neurons in the m-NTS (Kalia et al., $1985 \mathrm{a})$ and in the paraventricular nuclei of the hypothalamus (Ruggiero et al., 1984). These dopaminergic neurons may contribute to the TH-I terminals in the PBR and could have been overlooked by light microscopy due to the dense noradrenergic innervation. Moreover, most of the noradrenergic terminals in the PBR were probably undetected in the present ultrastructural analysis; TH appears to be more extensively associated with synaptic vesicles in noradrenergic than in dopaminergic terminals and is thus less accessible to immunoreagents (Pickel et al., 1975). The greater solubility of the enzyme contributes substantially to the ease of immunocytochemical detection in dopaminergic terminals. In perikarya and proximal processes the results of this study and an earlier one (Pickel et al., 1975) indicate that $\mathrm{TH}$ is easily detected throughout the cytoplasm of both noradrenergic and dopaminergic neurons without freezethawing or use of other methods for enhancing penetration.

The findings suggest that noradrenergic, adrenergic, and dopaminergic neurons provide an extensive innervation to the rat PBR and that many of the principally dopaminergic terminals detected in the present ultrastructural analysis modulate both non-catecholaminergic and a few catecholaminergic neurons within the area. Analysis of the functional implications and a more complete characterization of the specific catecholamine involved in these pathways await further investigation.

\section{Appendix}

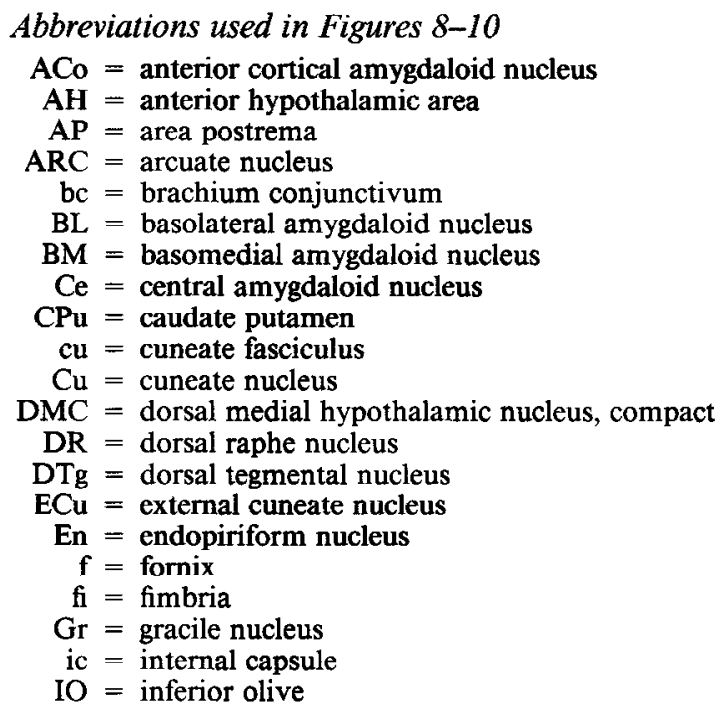




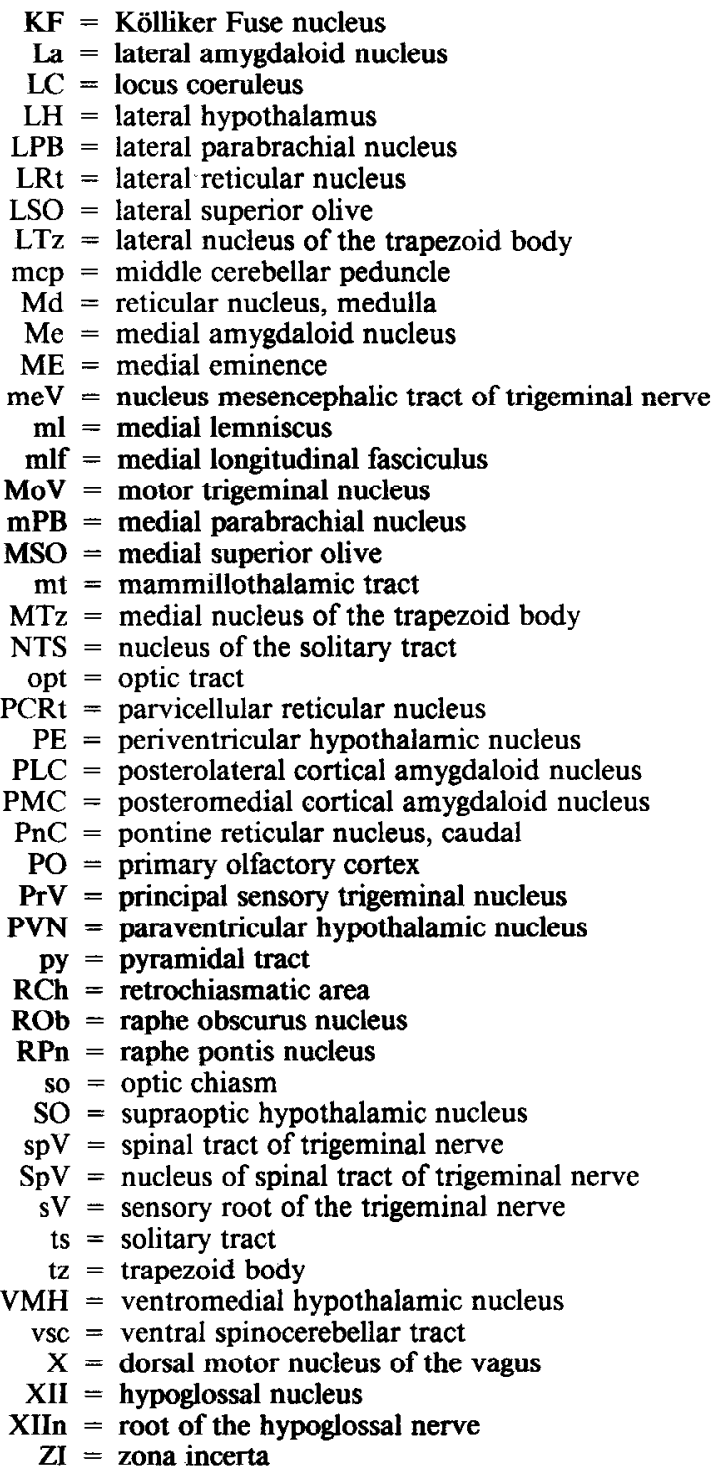

\section{References}

Amaral, D. G., and J. L. Price (1983) An air pressure system for the injection of tracer substances into the brain. J. Neurochem. 19: 3544.

Armstrong, D. M., V. M. Pickel, T. H. Joh, and D. J. Reis (1982a) Electron microscopic localization of tyrosine hydroxylase in the area postrema of rat. J. Comp. Neurol. 206: 259-272.

Armstrong, D. M., C. A. Ross, V. M. Pickel, T. H. Joh, and D. J. Reis (1982b) Distribution of dopamine-, noradrenaline-, and adrenalinecontaining cell bodies in the rat medulla oblongata demonstrated by the immunocytochemical localization of catecholamine biosynthetic enzymes. J. Comp. Neurol. 212: 173-187.

Bak, I. J. (1967) The ultrastructure of the substantia nigra and caudate nucleus of the mouse and the cellular localization of catecholamines. Exp. Brain Res. 3: 40-57.

Blessing, W. W., and D. J. Reis (1982) Inhibitory cardiovascular functions of neurons in the caudal ventrolateral medulla of the rat: Relationship to the area containing A1 noradrenergic cells. Brain Res. 253: 161-171.

Bolam, J. P., P. Somoggi, S. Tollerdell, and A. D. Smith (1981) A second type of striatonigral neuron: A comparison between labeled and Golgi stained neurons at the light and electron microscopic levels. Ncuroscience 6: 2141-2157.

Borison, H. L. (1974) Area postrema: Chemoreceptor trigger zone for vomiting-Is that all? Life Sci. 14: 1807-1817.

Bouyer, J. J., T. H. Joh, and V. M. Pickel (1984) Ultrastructural localization of tyrosine hydroxylase in rat nucleus accumbens. J. Comp. Neurol. 227: 92-103.

Brightman, M. W., and T. S. Reese (1975) Membrane specializations of ependymal cells and astrocytes. In The Nervous System, The Basic Neurosciences, Vol. 1, D. B. Tower, ed., pp. 267-277, Raven, New York.

Brown, D. L., and P. G. Guyenet (1984) Cardiovascular neurons of the nucleus paragigantocellularis lateralis with projections to the spinal cord. Am. J. Physiol. 247: R1009-R1016.

Bunney, B. S., J. R. Walters, R. H. Roth, and G. K. Aghajanian (1973) Dopaminergic neurons: Effect of antipsychotic drugs and amphetamines on single cell activity. J. Pharmacol. Exp. Ther. 185: 560571.

Cimarusti, D. L., K. Saito, J. E. Vaughn, R. Barber, R. Roberts, and P. E. Thomas (1979) Immunocytochemical localization of dopaminebeta-hydroxylase in rat locus ceruleus and hypothalamus. Brain Res. 162: 55-67.

Dählström, A., and K. Fuxe (1964) Evidence for the existence of monoamine neurons in the central nervous system. I. Demonstration of monoamines in the cell bodies of brainstem neurons. Acta Physiol. Scand. 62 (Suppl. 232): 1-55.

Descarries, L., D. Bosler, F. Berthelet, and M. H. Des Rosiers (1980) Dopaminergic nerve endings visualized by high resolution radioautography in adult rat neostriatum. Nature $284: 620-622$.

Everitt, B. J., T. Hökfelt, and L. Tereniers (1984) Differential coexistence of neuropeptide Y (NPY)-like immunoreactivity with catecholamines in the central nervous system of the rat. Neuroscience 11 : 443-462.

Ferrario, C. M., K. L. Barnes, J. E. Szilagyi, and K. B. Brosnihan (1979) Physiological and pharmacological characterization of the area postrema pressor pathways in the normal dog. Hypertension $1: 235-245$.

Fulwiler, C. E., and C. B. Saper (1984) Subnuclear organization of the efferent connections of the parabrachial nucleus in the rat. Brain Res. Rev. 7: 229-259.

Granata, A. R., D. A. Ruggiero, D. H. Park, T. H. Joh, and D. J. Reis (1983) Lesions of epinephrine neurons in the rostral ventrolateral medulla abolish vasodepressor components of baroreflex and cardiopulmonary reflex. Hypertension 5 (Suppl.): V80-V84.

Hedreen, J. (1980) Terminal degeneration demonstrated by the FinkHeimer method following lateral ventricular injection of 6-hydroxydopamine. Brain Res. Bull. 5: 425-436.

Hökfelt, T., L. Skirboll, J. F. Rehfeld, M. Goldstein, K. Markey, and O. Dann (1980) A subpopulation of mesencephalic dopamine neurons projecting to limbic areas contains a cholecystokinen-like peptide: Evidence from immunohistochemistry combined with retrograde tracing. Neuroscience 5: 2093-2124.

Hökfelt, T., K. Fuxe, M. Goldstein, and O. Johanson (1974) Immunohistochemical evidence for the existence of adrenaline neurons in the rat brain. Brain Res. 66: 235-251.

Hökfelt, T., B. J. Everitt, E. Theodorsson-Norheim, and M. Goldstein (1984a) Occurrence of neurotensin-like immunoreactivity in subpopulations of hypothalamic, mesencephalic, and medullary catecholamine neurons. J. Comp. Neurol. 222: 543-559.

Hökfelt, T., O. Johnasson, K. Fuxe, and M. Goldstein (1984b) Catecholamine neurons-Distribution and cellular localization as revealed by immunohistochemistry. In Catecholamines, U. Trendelenberg and N. Weiner, eds., Springer-Verlag, New York.

Hopkins, D. A., and G. Holstege (1978) Amygdaloid projections to the mesencephalon, pons and medulla oblongata in the cat. Exp. Brain Res. 32: 529-547.

Joh, T. H., and M. E. Ross (1983) Preparation of catecholamine synthesizing enzymes as immunogen for immunocytochemistry. In Immunocytochemistry, Vol. 3, A. C. Cuello, ed., pp. 121-138, John Wiley, Oxford IBRO Handbook Series, New York.

Joh, T. H., C. Gegham, and D. J. Reis (1973) Immunochemical demonstration of increased tyrosine hydroxylase protein in sympathetic ganglia and adrenal medulla elicited by reserpine. Proc. Nat. Acad. Sci. USA 70: 2767-2771.

Kalia, M., K. Fuxe, and M. Goldstein (1985a) Rat medulla oblongata. II. Dopaminergic, noradrenergic (A1 and A2) and adrenergic neurons, nerve fibers and presumptive terminal processes. J. Comp. Neurol. 233: 308-332.

Kalia, M., K. Fuxe, and M. Goldstein (1985b) Rat medulla oblongata. III. Adrenergic ( $\mathrm{Cl}$ and $\mathrm{C} 2$ ) neurons, nerve fibers and presumptive terminal processes. J. Comp. Neurol. 233: 333-349. 
King, G. W. (1980) Topology of ascending brainstem projections to nucleus parabrachialis in the cat. J. Comp. Neurol. 191: 615-638.

Levitt, P., and R. Y. Moore (1979) Origin and organization of brainstem catecholamine innervation in the rat. J. Comp. Neurol. 186 : 505-528.

Ljungdahl, A., T. Hökfelt, and G. Nilsson (1978) Distribution of substance P-like immunoreactivity in the central nervous system of the rat. I. Cell bodies and nerve terminals. Neuroscience 3: 861-943.

Loewy, A. D., and H. Burton (1978) Nuclei of the solitary tract: Efferent projections to the lower brainstem and spinal cord of the cat. J. Comp. Neurol. 181: 421-450.

Loewy, A. D., and S. McKellar (1980) The neuroanatomical basis of central cardiovascular control. Fed. Proc. 39: 2495-2503.

Mantyh, P. W., and S. P. Hunt (1984) Neuropeptides are present in projection neurones at all levels in visceral and taste pathways from periphery to sensory cortex. Brain Res. 292: 299-311.

Mesulam, M.-M. (1978) Tetramethylbenzidine for horseradish peroxidase neurohistochemistry: A non-carcinogenic blue reaction product with superior sensitivity for visualizing neural afferents and efferents. J. Histochem. Cytochem. 26: 106-117.

Milner, T. A., and V. M. Pickel (1986a) Ultrastructural localization and afferent sources of substance $P$ in the rat parabrachial region. Neuroscience 17: 687-707.

Milner, T. A., and V. M. Pickel (1986b) Neurotensin in the rat parabrachial region: Ultrastructural localization and extrinsic sources of immunoreactivity. J. Comp. Neurol. 247: 326-343.

Milner, T. A., T. H. Joh, R. J. Miller, and V. M. Pickel (1984) Substance $P$, neurotensin, enkephalin and catecholamine-synthesizing enzymes: Light microscopic localizations compared with autoradiographic label in solitary efferents to the rat parabrachial region. J. Comp. Neurol. 226: 434-447.

Milner, T. A., J. Chan, V. J. Massari, W. H. Oertel, D. Park, T. H. Joh, D. J. Reis, and V. M. Pickel (1985) Ultrastructure and synaptic interactions of adrenergic and GABAergic neurons in the rat rostral ventrolateral medulla. Soc. Neurosci. Abstr. 11:570.

Mraovitch, S., M. Kumada, and D. J. Reis (1'982) Role of the nucleus parabrachialis in cardiovascular regulation of cat. Brain Res. 232: 5775 .

Norgren, R. (1978) Projections from the nucleus of the solitary tract in the rat. Neuroscience 3: 207-218.

Palkovits, M., and D. M. Jacobowitz (1974) Topographic atlas of catecholamine and acetylcholinesterase-containing neurons in the rat brain. II. Hindbrain (mesencephalon, rhombencephalon). J. Comp. Neurol. 157: 29-42.

Paxinos, G., and C. Watson (1982) The Rat Brain in Stereotaxic Coordinates, Academic Press, New York.

Pickel, V. M. (1981) Immunocytochemical methods. In Neuroanatomical Tract Tracing Methods, L. Heimer and M. J. Robards, eds., pp. 483-509, Plenum, New York.

Pickel, V. M., and D. M. Armstrong (1984) Ultrastructural localization of monoamines and peptides in rat area postrema. Fed. Proc. 43: 2949-2951.

Pickel, V. M., T. H. Joh, and D. J. Reis (1975) Ultrastructural localization of tyrosine hydroxylase in noradrenergic neurons of brain. Proc. Natl. Acad. Sci. USA 72: 659-663.

Pickel, V. M., T. H. Joh, and D. J. Reis (1976) Monoamine-synthesizing enzymes in central dopaminergic, noradrenergic and serotonergic neurons: Immunocytochemical localization by light and electron microscopy. J. Histochem. Cytochem. 24: 792-806.

Pickel, V. M., S. C. Beckley, T. H. Joh, and D. J. Reis (1981) Ultrastructural immunocytochemical localization of tyrosine hydroxylase in the neostriatum. Brain Res. 225: 373-385.

Pickel, V. M., J. H.-L. Chan, T. H. Joh, and A. Beaudet (1983) Vagal afferent and serotonergic terminals form synapses with catecholaminergic neurons in rat area postrema. Soc. Neurosci. Abstr. 9:1127.

Pickel, V. M., J. Chan, T. H. Joh, and V. J. Massari (1984) Catecholaminergic neurons in the medial nuclei of the solitary tracts receive direct synapses from GABAergic terminals: Combined colloidal gold and peroxidase labeling of synthesizing enzymes. Soc. Neurosci. Ábstr. 10: 537.

Pickel, V. M., J. Chan, and T. A. Milner (1986) Autoradiographic detection of secondary antiserum: A sensitive light and electron microscopic labeling method compatible with peroxidase immunocytochemistry for dual localization of neuronal antigens. J. Histochem. Cytochem. 34: 707-718.

Ricardo, J. A., and E. T. Koh (1978) Anatomical evidence of direct projections from the nucleus of the solitary tract to the hypothalamus, amygdala and other forebrain structures in the rat. Brain Res. 153: $1-16$.

Ross, C. A., D. A. Ruggiero, D. H. Park, T. H. Joh, A. T. Sved, J. Fernandez-Pardal, J. M. Saavedra, and D. J. Reis (1984) Tonic vasomotor control by the rostral ventrolateral medulla: Effect of electrical or chemical stimulation of the area containing $\mathrm{Cl}$ adrenergic neurons on arterial blood pressure, heart rate and plasma catecholamines and vasopressin. J. Neurosci. 4: 474-494.

Ruggiero, D. A., C. A. Ross, M. Kumada, and D. J. Reis (1982) Reevaluation of projections from the mesencephalic trigeminal nucleus to the medulla and spinal cord: New projections. A combined retrograde and anterograde horseradish peroxidase study. J. Comp. Neurol. 206: 278-292.

Ruggiero, D. A., H. Baker, T. H. Joh, and D. J. Reis (1984) Distribution of catecholamine neurons in the hypothalamus and preoptic region of mouse. J. Comp. Neurol. 223: 556-582.

Ruggiero, D. A., C. A. Ross, M. Anwar, D. H. Park, T. H. Joh, and D. J. Reis (1985) Distribution of neurons containing phenylethanolamine- $\mathrm{N}$-methyltransferase in medulla and hypothalamus of rat. $\mathrm{J}$. Comp. Neurol. 239: 127-154.

Rye, D. B., C. B. Saper, and B. H. Wainer (1984) Stabilization of the tetramethylbenzidine (TMB) reaction product: Application for retrograde and anterograde tracing, and combination with immunohistochemistry. J. Histochem. Cytochem. 32: 1145-1153.

Saper, C. B., and A. D. Loewy (1980) Efferent connections of the parabrachial nucleus in the rat. Brain Res. 197: 291-317.

Saper, C. B., A. D. Loewy, L. W. Swanson, and W. M. Cowan (1976) Direct hypothalamo-autonomic connections. Brain Res. 117: 305312.

Saper, C. B., L. W. Swanson, and W. M. Cowan (1979) An autoradiographic study of the efferent connections of the lateral hypothalamic area in the rat. J. Comp. Neurol. 183: 689-706.

Sawchenko, P. E., and L. W. Swanson (1982) The organization of noradrenergic pathways from the brainstem to the paraventricular and supraoptic nuclei in the rat. Brain Res. Rev. 4: 275-322.

Schwyn, R. C., and C. A. Fox (1974) The primate substantia nigra: A Golgi and electron microscopic study. J. Hirnforsch. 15: 95-126.

Sternberger, L. A. (1979) Immunocytochemistry, John Wiley, New York.

Sumal, K. K., W. W. Blessing, T. H. Joh, D. J. Reis, and V. M. Pickel (1983) Synaptic interaction of vagal afferents and catecholaminergic neurons in the rat nucleus tractus solitarius. Brain Res. 277: 31-40.

Svensson, T. H., B. S. Bunney, and G. K. Aghajanian (1975) Inhibition of both noradrenergic and serotonergic neurons in the brain by the adrenergic agonist clonidine. Brain Res. 92: 291-306.

Swanson, L. W. (1982) The projections of the ventral tegmental arca and adjacent regions: $A$ combined fluorescent retrograde tracer and immunofluorescence study in the rat. Brain Res. Bull. 9: 321-353.

Swanson, L. W., and B. K. Hartman (1975) The central adrenergic system. An immunofluorescence study of the location of cell bodies and their efferent connections in the rat utilizing dopamine- $\beta$-hydroxylase as a marker. J. Comp. Neurol. 163: 467-505.

Takeuchi, Y., and D. A. Hopkins (1984) Light and electron microscopic demonstration of hypothalamic projections to the parabrachial nuclei in the cat. Neurosci. Lett. 46: 53-58.

Takeuchi, Y., J. H. McLean, and D. A. Hopkins (1982) Reciprocal connections between the amygdala and parabrachial nuclei: Ultrastructural demonstration by degeneration and axonal transport of horseradish peroxidase in the cat. Brain Res. 239: 583-588.

Wainer, B. H., and D. B. Rye (1984) Retrograde horseradish peroxidase tracing combined with localization of choline acetyltransferase immunoreactivity. J. Histochem. Cytochem. 32: 439-443.

Westlund, K. N., R. M. Bowker, M. G. Ziegler, and J. D. Coulter (1983) Noradrenergic projections to the spinal cord of the rat. Brain Res. 263: $15-31$. 